\title{
COMPUTATIONAL CHEMISTRY APPLIED TO STUDIES OF ORGANIC CONTAMINANTS IN THE ENVIRONMENT: EXAMPLES BASED ON BENZO $[a]$ PYRENE
}

\author{
JAMES D. KUBICKI
}

Department of Geosciences and The Earth and Environmental Systems Institute, The Pennsylvania State University, 308 Deike Building,

University Park, Pennsylvania 16802;

kubicki@geosc.psu.edu

\begin{abstract}
The topics of DNA adduct structure, biodegradation mechanisms, photo-chemistry, and adsorption of polycyclic aromatic hydrocarbons (PAHs) are discussed using benzo $[a]$ pyrene and its partial oxidation products as an example. The use of classical mechanical, semi-empirical, and $a b$ initio computational techniques are discussed in terms of their ability to answer important questions regarding the environmental fate of this important carcinogenic compound. The role of $\mathrm{H}$-bonding variation with computational technique was analyzed and significant errors are likely when this parameter is predicted by classical force field simulations or semi-empirical calculations. The stability of the conformations of benzo[a]pyrene also change with computational method although the density functional theory (DFT) and second-order Møller-Plessett (MP2) methods used here converge to similar relative energies. Analysis of the relationship among HOMO-LUMO gaps, triplet and singlet excitation energies, and phototoxicity suggests that the HOMO-LUMO gaps are not the true parameter related to phototoxicity but a correlation between HOMO-LUMO gaps and excitation energies gives the appearance of a cause-and-effect relationship. Methods for predicting the water-soot partition coefficient of PAHs and the complexation of partial oxidation products with cations and metals in the environment are also discussed.
\end{abstract}

\section{INTRODUCTION}

\section{Why Is Assessing Bioavailability and Fate Important?}

A traditional approach to determining environmental risk and creating regulatory limits has been to measure the total amount of a substance present and set a maximum concentration value that should not be exceeded. However, this approach neglects the exact state of the contaminant; and the state of a compound can be the dominant factor in predicting the environmental risk associated with a particular contaminant. Examples of toxicity reduction are numerous for both metals and organic species (see Alexander, 1994 for a review); hence, a revision of the general methodology for determining acceptable concentration limits should be made. The U.S. Environmental Protection Agency (USEPA) has made strides in this direction recently (Meyer and others, 1999; USEPA, 2000; DiToro and others, 2001), but changing past regulations and the basis of environmental laws is a daunting task. One downside of assessing speciation in the environment is that it complicates the task of analyzing and monitoring already complex chemistry. The advantage is that we will better be able to allocate our resources to maximize the benefit/cost ratio of environmental remediation. For example, determining that the toxic species of a metal such as $\mathrm{Cu}^{2+}$ (Sunda and Huntsman, 1998) is only 1 percent of the total $\mathrm{Cu}$ in a water body may potentially save billions in clean up costs throughout the nation. Pignatello (1986) showed that ethylene dibromide (EDB) present in soils failed to biodegrade when ${ }^{14} \mathrm{C}$-labeled EDB spiked into the same soil degraded rapidly. These results demonstrated that aging of organic contaminants (that is, diffusion into micorpores or natural organic matter) could significantly alter their bioavailability. 
Environmental effects depend upon bioavailability.-A main reason why details of contaminant behavior are important is that environmental risk depends upon bioavailability, that is the capacity of organisms in a particular environment to assimilate a given contaminant. One good example is found in the work of McGroddy and Farrington (1995) where polycyclic aromatic hydrocarbons (PAHs) were persistent in sediments over a long period when equilibrium partitioning models between sediment and pore water predicted that these compounds would have disappeared long ago (Alexander, 1995). Although the PAHs were still present and could be considered a risk, the fact that they were recalcitrant (that is, resisting biodegradation or transport) suggested that they may have a reduced environmental risk. Further research has demonstrated that this type of sequestration (that is, hiding a compound within a naturally occurring substance such as minerals or natural organic matter) is fairly common and probably naturally reduces environmental risk (for example, Stewart and others, 2003; Semple and others, 2003). Thus, we may be overestimating environmental risk and overspending on some remediation projects.

Geochemical factors (for example, mineralogy, NOM, et cetera) affect bioavailability. - Consequently, analysis of the mineralogy and natural organic matter (NOM) in soils and sediments should accompany the analysis for contaminants of interest. Details of mineral composition and microporosity can dramatically alter bioavailability (McCarthy and others, 1985; Murphy and others, 1990, 1992; Farrell and Reinhard, 1994). Generally, the percentage of organic matter is the most detail included with regards to the organic geochemistry of a site. Characterization of the NOM is not conducted even though the quality of organic matter has a significant influence on bioavailability (Huang and Weber, 1997; Luthy and others, 1997). For example, PAHs included in sediments via the deposition of soot that was co-formed with the PAHs can essentially exclude these contaminants from biodegradation (McGroddy and Farrington, 1995). Funds and expertise are not often available for this type of extensive analysis before remediation efforts are conducted, so overspending on cleanup efforts results.

Biodegradation common but complete mineralization does not always occur. - On the other side of the coin, reactions of contaminants in the environment may actually increase risk in some instances. Bioremediation efforts are commonly assumed to go to complete mineralization (Note: "Mineralization" in the bioremediation community means conversion to $\mathrm{CO}_{2}$ and $\mathrm{H}_{2} \mathrm{O}$, not precipitating minerals.) if the contaminant of concern (for example, naphthalene) is disappearing from the system of interest. Unfortunately, biodegradation of many common contaminants occurs through a multi-step process and complete mineralization is not assured. Metabolic intermediates that form during this process may be both more soluble (and mobile) and toxic (Wilson and others, 1996; Wilson and Madsen, 1996; Pisutpaisal, ms, 2003). One example of this is an aquifer that was contaminated with jet fuel (Long and Aelion, 1999). Biodegradation or natural attenuation occurred, but subsequent toxicity tests revealed toxicity due to the formation of acidic metabolic intermediates. Reasons for this behavior will be discussed in more detail below, but it is often the metabolite of an organic pollutant that does harm within the organism rather than the pollutant itself per se. Predicting metabolic intermediates and their behavior should be an important aspect of evaluating environmental risk and remediation strategies.

\section{What Role can Computational Chemistry Play in Assessing Bioavailability and Fate?}

From the references cited above, one can begin to see the importance of contaminant interactions with natural materials in predicting bioavailability and fate in environmental biogeochemistry. The task is somewhat overwhelming considering the number of compounds and variables that need to be considered. Although analytical work and toxicology will be the primary modes of assessing speciation and risk, computational chemistry can play a role in understanding these types of observations 
and limiting the number of variables that need to be considered. This approach has been successfully applied in the pharmaceutical industry for a number of years as candidate compounds are pre-screened before more costly experimentation begins (for example, Lepre and others, 2002; Cheng and Merz, 2003).

Computation can complement experimental studies on toxicity mechanisms.-Biochemists are currently using molecular modeling techniques to assess the molecular-level interactions between pollutants and organisms (see Schultz and others, 2003 for a review; Parthasarathi and others, 2003). Such details can be used to elucidate toxicity mechanisms that are extremely difficult to obtain experimentally. Molecular toxicity mechanisms are important because general principles may then be derived to predict which compounds will have significant biological impacts. For instance, there are a large number of different PAH compounds, but the carcinogenicity between compounds varies dramatically. Broyde and coworkers (Perlow and Broyde, 2001, 2003; Perlow and others, 2002) have been investigating why benzo $[a]$ pyrene has a high carcinogenicity by modeling its interaction with DNA. Subtle structural differences may exist in the DNA adducts formed that prevent repair of the DNA and lead to subsequent development of cancers. Hence, it is not just the fact that the metabolite forms a DNA adduct; the more important consideration is whether or not the organism's repair mechanisms will detect and fix this defect before it has a chance to replicate itself. This research will be discussed in more detail below. The ability to predict when this chemistry will occur can be a powerful tool in assessing the potential environmental risk of contaminants.

Development of Quantitative Structure-Activity Relationships (QSARs) and screening for potentially harmful effects. - Once general principles have been discovered that govern toxicity, carcinogenicity, et cetera, then one can begin to use Quantitative StructureActivity Relationships (QSARs) to screen compounds for further study (Schultz and others, 2003; Trohalaki and Pachter, 2003). The term QSAR is somewhat misleading in this context. Instead of only using structural parameters, any type of molecular property can be used and often many in combination. For example, particular functional groups may be a structural parameter that is used in predicting toxicity, but other parameters such as ionization potentials, HOMO-LUMO gaps, and aqueous solubilities can also be important. Perhaps the term Quantitative Activity Relationships (QAR) would be more appropriate. Candidate compounds that score highly based on similarities to other problem compounds can be selected for more extensive experimental study. This technique is well-established in biochemistry and could become a common tool in environmental biogeochemistry as well.

Molecular modeling studies can help predict the metabolic intermediates.-Another way that computational chemistry can be used in this task is to model the biodegradation or biologically catalyzed redox reactions of contaminants (Little and others, 1999; Brown and others, 2002). Once tested against well-known experiment systems for accuracy, relatively quick and inexpensive calculations can be performed on large suites of compounds to help predict which metabolic intermediates may form and how they will behave in the environment. Identification of these metabolic intermediates may be difficult in field or laboratory samples, because they do not appear in high concentrations. However, if the analytical chemist knows a priori which compounds to search for, then the task becomes more amenable.

Computational chemistry useful in understanding the role of sorption.- - Lastly, computational chemistry is a useful method for understanding how pollutants interact with natural materials such as minerals and NOM (Kubicki and others, 1999; Farrell and others, 2002; Luo and Farrell, 2003; Neal and others, 2003). The combination of spectroscopy, wet chemistry experiments, and molecular modeling can be powerful in this regard because each technique supplies different pieces of the puzzle in order to 
generate a complete and detailed picture of the system under study. Zhang and others (2004), for example, used this approach to obtain an atomic-level structure of $\mathrm{Sr}^{2+}$ and $\mathrm{Zn}^{2+}$ surface complexes on the (110) surface of rutile $\left(\mathrm{TiO}_{2}\right)$. In addition, this atomic-level picture was used to constrain macroscopic thermodynamic calculations of adsorption at this surface which was used to model bulk isotherm experiments. In this manner, assumptions in the macroscopic modeling approach were replaced with more accurate numbers for bond lengths which resulted in more accurate surface complexation modeling predictions. In addition, the surface complexation modeling transported the spectroscopic and molecular modeling information from the realm of academic interest into real world applicability.

One example of where experiment and molecular modeling have been used to complement one another is in the studies of Gustafsson and coworkers (Gustafsson and others, 1997; Bucheli and Gustafsson, 2000; Bucheli and Gustafsson, 2003) in parallel with modeling done by Kubicki $(2002,2003)$ on PAH and PCB adsorption onto soot. The experimental work in this case was key for identifying soot as an important component of soils and sediments with respect to adsorption of these hydrophobic organic contaminants. Adsorption experiments were able to produce $\mathrm{K}_{\mathrm{d}}$ values for suites of PAHs and PCBs in order to predict their partitioning behavior in the environment. However, the mechanisms of interaction with the soot were difficult to ascertain due to the complex nature of soot and the similarities between soot and the sorbates of interest. Kubicki (2002, 2003) used the same suites of compounds in the Bucheli and Gustafsson $(2000,2003)$ studies and was able to produce good correlations between the calculated $\Delta \mathrm{E}_{\text {ads }}$ and the observed $\mathrm{K}_{\mathrm{d}}$ values. This resulted in two advantages. The modeling verified that the soot could account for much of the recalcitrant PAHs and PCBs in the soils and sediments. In addition, the modeling work could be done on compounds that were problematic experimentally (for example, benzene due to high volatility). Furthermore, the modeling work was used to predict values for $\mathrm{K}_{\mathrm{d}}$ 's not originally produced. The theoretical work is also capable of producing predictions more rapidly than experiment because some of the adsorption work requires 4 months of aging.

\section{Brief Literature Review of Some Representative Studies}

The above discussion indicates that there is an overwhelming amount of research performed and to be performed assessing the bioavailability and fate of contaminants. A review of the entire field is impractical, so this paper will focus on a specific example to illustrate methods, interdisciplinary connections, and opportunities for future research. The example compound selected is benzo $[a]$ pyrene $(\mathrm{BaP})$. A number of reasons led to the selection of $\mathrm{BaP}$ as an illustrative example. First, $\mathrm{BaP}$ is highly carcinogenic (Harvey, 1991) and thus of interest to human health. Second, BaP is common in the environment because it has numerous sources such as fossil fuels, diesel and auto exhaust, cigarette smoke, and broiled foods (Grimmer, 1993; Perrin and others, 1993; Phillips, 1999). Third, a number of papers modeling this compound have been published recently, making synthesis of each type of study a simpler task. The organization of this paper will be the reverse of the environmental processes leading to human health impacts (that is, source, transport, and exposure). This discussion will begin with biochemical modeling of BaP-DNA adducts because such studies motivate the environmental research, and their detailed elegance defines the level to which the biogeochemical modeling studies should strive to achieve.

A number of important factors in assessing environmental fate and bioavailability of organic contaminants will not be discussed in this paper, but they are worth mentioning so the interested reader will be able to see how the molecular level modeling presented here fits into the bigger picture. First, field or regional scale transport of contaminants is necessary for determining where the compounds of 
interest will be found. Studies such as McLachlan and others (2002) are examples of this type of research. Furthermore, the macroscopic level chemistry of contaminantbiota interactions should be understood in order to put the molecular level work in context (Hunter and others, 1998; Boudreau, 1999; Wania and McLachlan, 2001; Meile and others, 2003). An important link between the larger scale and molecular level research is the generation of self-consistent thermodynamic data (for example, Beyer and others, 2002) and QSARs (for example, Kosian and others, 1998; He and others, 2003) to rapidly predict general environmental effects of different compounds.

Computational chemistry can be an important partner in these endeavors. Thermodynamic data can be confirmed or tested in many instances by theoretical methods (Stewart, 2004). Molecular properties, such as $\log \left(\mathrm{K}_{\mathrm{ow}}\right)$ and HOMO-LUMO gaps, can also be computed that help predict macroscopic behavior of compounds (Veith and others, 1995; Kubicki and others, 1999). Additionally, computational chemistry can be employed to help interpret experimental observations as well as extrapolate experimental results into systems where experiments are problematic for practical reasons (Kubicki, 2000; Govers and others, 2002; Kubicki, 2003).

\section{METHODS}

The theoretical methods employed include classical molecular mechanics simulations (Frenkel and Smit, 2002), semi-empirical calculations (Stewart, 1990), and $a b$ initio theory (Cramer, 2002). Cygan and Kubicki (2001) contains a compilation of chapters on many of these techniques as applied in geochemistry.

The classical molecular mechanics simulations were performed using the Cerius ${ }^{2}$ suite of programs (Accelrys Inc., San Diego, CA) and the COMPASS (Sun, 1998) force field. Either energy minimization or molecular dynamics simulations (Cygan, 2001) were used to predict molecular structures.

Semi-empirical PM5 calculations (Stewart, 2004) were carried out with the program CAChe (Fujitsu Ltd.). A $b$ initio calculations were done with the hybrid molecular orbital/density functional theory approach (MO/DFT; Foresman and Frisch, 1997), Møller-Plessett second-order perturbation theory (MP2; Møller and Plessett, 1934), configuration interaction singles (CIS; Foresman and others, 1992), and timedependent density functional theory (TDDFT; Stratmann and others, 1998). For the MO/DFT and TDDFT, the Becke (1993) 3-parameter exchange functional and the Lee-Yang-Parr (Lee and others, 1988) correlation functional (that is, B3LYP) were chosen. A number of basis sets were used to describe the electron densities, but the most common were the 6-31G(d) and 6-311G $(\mathrm{d}, \mathrm{p})$ basis sets (Hehre and others, 1972; Krishnan and others, 1980; McLean and Chandler, 1980). Gaussian 03 (Frisch and others, 2003) was used to carry out these ab initio calculations.

Relevant results generated from these calculations can take many forms, but the predictions made here generally fall into the areas of structure, potential energies, and electronic excitation energies. Structural information is straightforward to derive from the calculations because the input and output positions of all atoms are always known in this work. The energies discussed are generally relative potential energy changes (not including zero-point energies). Although more rigorous methods are available for predicting thermodynamic stabilities of species, this paper seeks to compare various methods such as molecular mechanics, semi-empirical, and ab initio calculations. Each has its own reference state, so comparisons are simplified by focusing on the relative potential energy changes predicted by each method. This puts all methods on the same footing. Electronic excitation energies are calculated either by predicting the positions of electronic orbitals (that is, HOMO-LUMO gap calculations) or by directly modeling the electronic density in the excited state. The latter should be more accurate but is also more time-consuming. 
RESULTS

\section{Modeling DNA Adducts}

Broyde and coworkers (Perlow and Broyde, 2001, 2002, 2003; Perlow and others, 2002) have performed a series of studies using MD simulation techniques to examine how the $(+)$-anti-BaP diol epoxide (BPDE - fig. 1) interacts with DNA to form the $(+)$-trans-anti-BaP diol epoxide- $\mathrm{N}^{2}-\mathrm{dG}((+)-t a-[\mathrm{BP}] \mathrm{G}-$ fig. 2) adduct which is not recognized by DNA polymerase and allows for mismatch of adenine with guanine (that is, a G-to-T transverse mutation). Such studies emphasized the role of intermediate oxidation products of contaminants in producing negative health effects and the subtle structural features that must develop in order for an organism's normal repair mechanisms to fail to detect that the DNA has been damaged.

The structure of BPDE itself is of interest as a metabolic intermediate formed by partial oxidation of benzo $[a]$ pyrene. Four conformers are possible-anti-quasidiequatorial, anti-quasidiaxial, syn-quasidiequatorial, and syn-quasidiaxial depending on the relative positions of the $\mathrm{OH}$ groups (fig. 1). Brown and others (2002) investigated the relative stabilities of each configuration in water using MD simulations and found that $\mathrm{H}$-bonding of water was significant, especially for the more stable anti configurations. Thus, investigating the relative predicted stabilities of each conformation as a function of computational method and solvation is worthwhile.

Table 1 lists the relative potential energies of each conformation as a function of four computational methods-PM5, B3LYP/6-31G(d), MP2/6-31G(d)//B3LYP/6$31 \mathrm{G}(\mathrm{d})$, and MP2/6-31G $(\mathrm{d})$. Although none of these methods represents an extremely high level of theory, the comparison of results illustrates a point about the dependence of predictions on computational level. Both the molecular mechanics and semiempirical methods (COMPASS and PM5) give different minimum energy structures and energies between conformations compared to the ab initio methods (B3LYP and MP2). This demonstrates that even when the lower level methods are able to reproduce molecular structures fairly well (fig. 3), energies are not always accurate. Errors in calculated energies will translate into inaccurate predictions of thermodynamic properties and kinetic energy barriers, so this point is critical. Model results should be compared with experiment whenever possible and against higher level theoretical results to ensure that the simpler method converges to a reasonably accurate answer.

Table 2 presents the relative energies of the same four BPDE conformers in the presence of a model aqueous solvent (COMPASS/3-D periodic MD with $338 \mathrm{H}_{2} \mathrm{O}$ molecules; PM5/AMSOL-Urban and others, 1992; B3LYP/IEFPCM-Cancès and others, 1997). Solvation effects allow re-distribution of the electrons throughout the molecule, and they also tend to favor configurations with higher dipole moments. Consequently, the aqueous model in each case predicts a different conformer to be the stable configuration compared to the gas-phase calculations using the same method (table 1). In addition, the relative energy differences between conformers changes even when comparing one method to its counterpart in table 1. Often, computational chemists have neglected the solvent for reasons of convenience (that is, savings in computational time) and because many neutral, organic compounds will have limited solvation effects. However, the need to account for solvation has been recognized for some time and a number of groups have made great strides in developing algorithms to account solvation effects (for examples, see the references above.). These results illustrate the point that the model simulations must include all important components of the system in order to be useful. This warning is summed up in the statement- "A theory has only the alternative of being right or wrong. A model has a third possibility: it may be right, but irrelevant." (Manfred Eigen as quoted in Cygan, 2001).

Differences between the control dCTP: $(+)-t a-[\mathrm{BP}] \mathrm{G}$ (dCTP $=$ deoxycytidine triphosphate) as modeled with semi-empirical PM5 (Stewart, 2004) and ab initio 

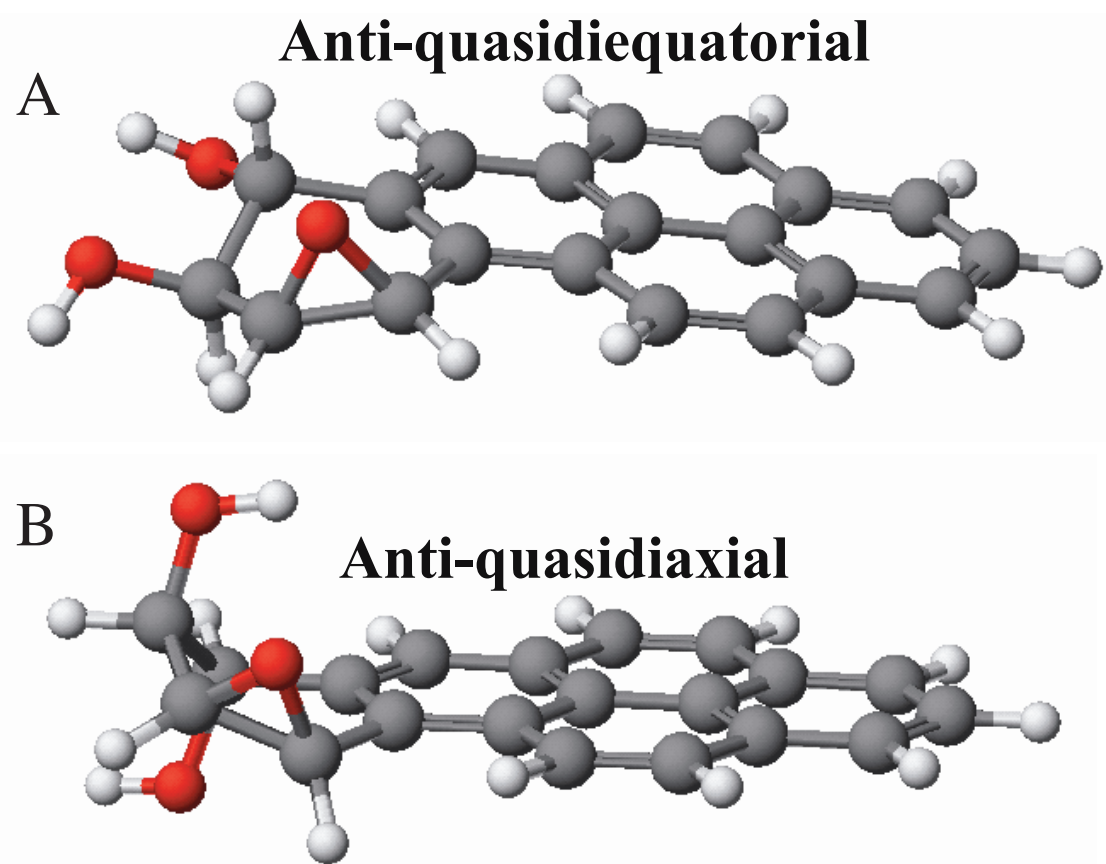

Syn-quasidiequatorial
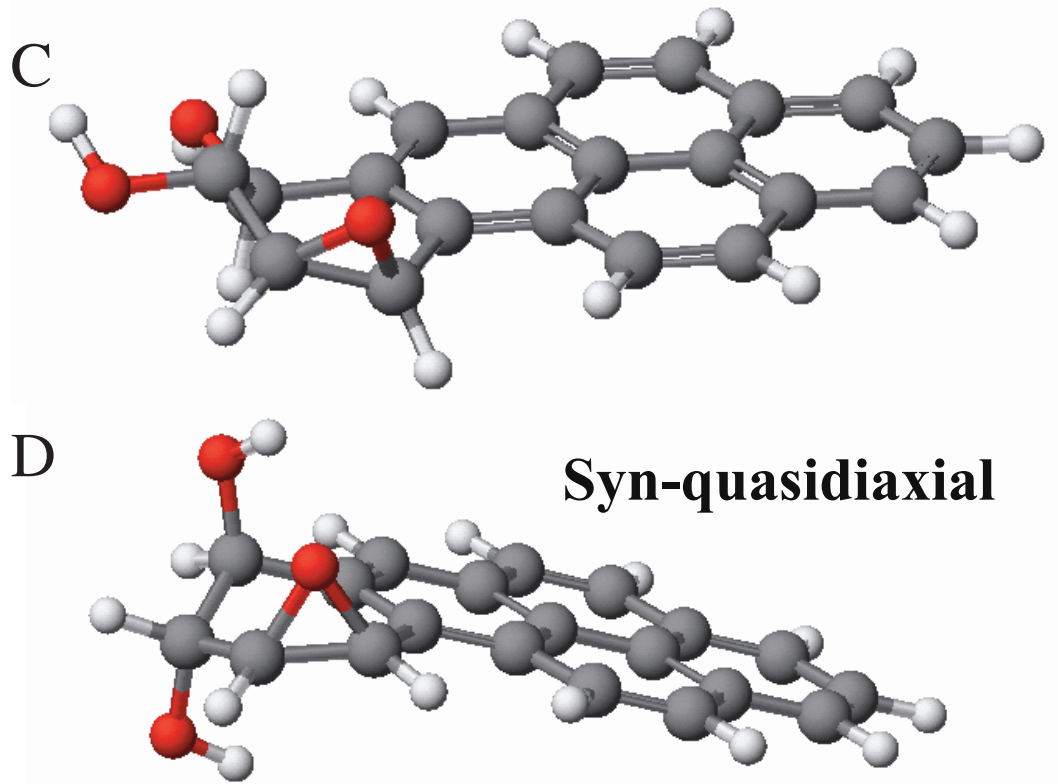

Fig. 1. Four conformers of the benzo[a]pyrene diol epoxide (BPDE) molecule as calculated with B3LYP / 6-311++G(d,p) using Gaussian 03 (Frisch and others, 2003). Subtle structural differences result in significant changes to the calculated potential energies. Such changes can be reflected in the manner in which such a metabolite forms a DNA adduct. 

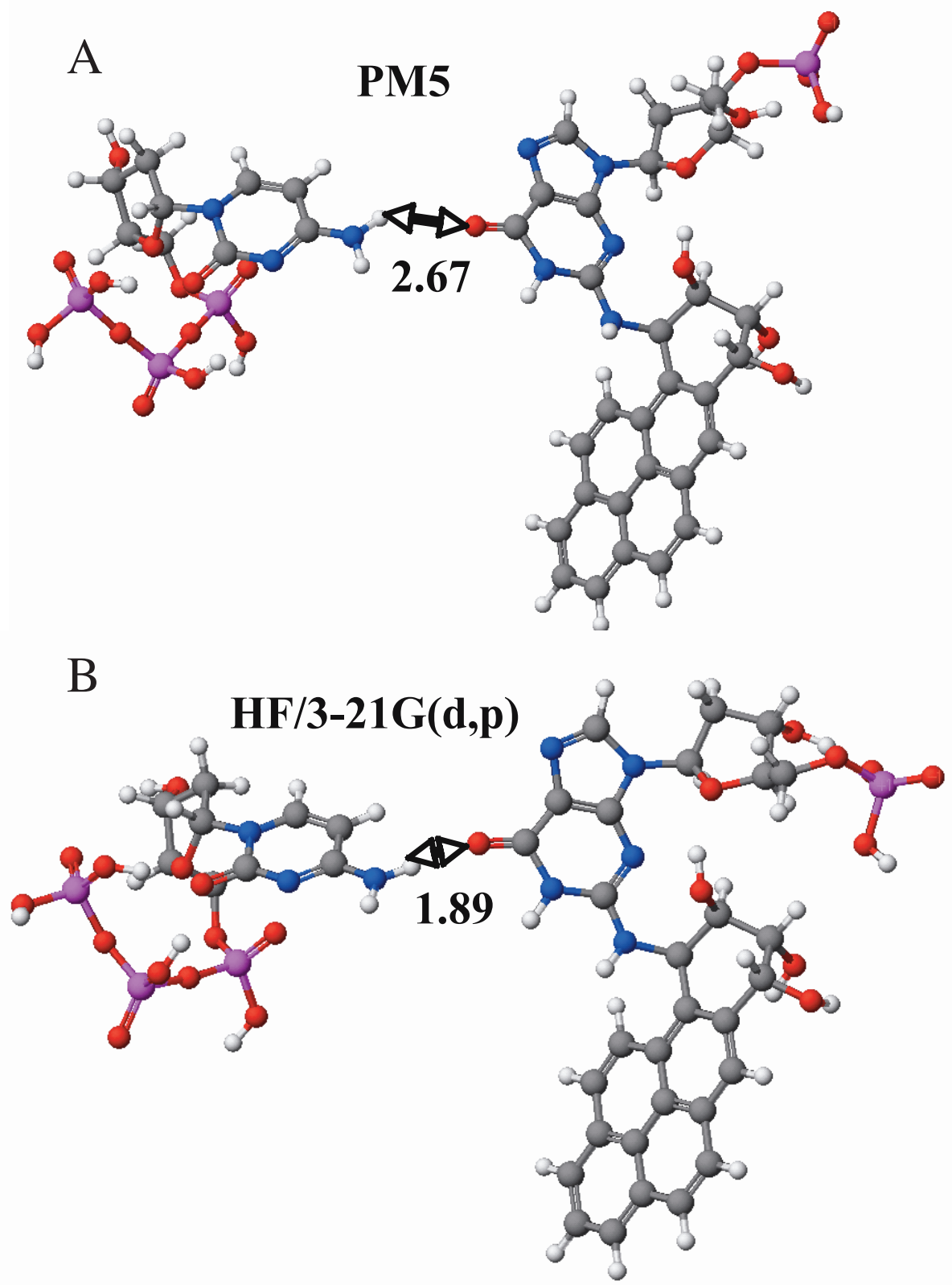

Fig. 2. Calculated model structures of the BPDE-DNA adduct based on (A) PM5 and (B) HF/321G(d,p) methodologies. This model was excised from Perlow and Broyde (2003) to represent the recognition step of DNA repair, but it does not represent the DNA structure. The main point of difference is that significant changes in predicted H-bonding result from using various computational methods. Hbonding is difficult to describe accurately; and, although the HF method here may be more accurate than the PM5 method, HF calculations are generally not considered to be very accurate in regards to predicting H-bonding. 
TABLE 1

Comparison of relative potential energies $(\mathrm{kJ} / \mathrm{mol})$ for four conformations of the benzo[a]pyrene diol epoxide in the gas-phase

\begin{tabular}{lccccc}
\hline Conformation & COMPASS & PM5 & $\begin{array}{c}\mathrm{B} 3 \mathrm{LYP} / \\
6-31 \mathrm{G}(\mathrm{d})\end{array}$ & $\begin{array}{c}\mathrm{MP} 2 / \\
6-31 \mathrm{G}(\mathrm{d})\end{array}$ & $\begin{array}{c}\mathrm{MP}^{\dagger} \\
6-31 \mathrm{G}(\mathrm{d})\end{array}$ \\
\hline anti-eq & +4 & +24 & 0 & 0 & 0 \\
anti-ax & +21 & +11 & +38 & +33 & +37 \\
syn-eq & 0 & +21 & +6 & +6 & +6 \\
syn-ax & +25 & 0 & +21 & +22 & +6 \\
\hline
\end{tabular}

$\dagger=$ in B3LYP/6-31G(d) structure.

$\mathrm{HF} / 3-21 \mathrm{G}(\mathrm{d}, \mathrm{p})$ calculations can be seen in figure 2. The model system in figure 2 is not meant to represent the true configuration as presented in Perlow and Broyde (2001, 2002, 2003) because these components of the system have been removed from the overall DNA molecule. Consequently, the long-range constraints on the structure have been removed. Slicing of the model was performed to allow for full Hartree-Fock calculations on the entire model. Phosphorous atoms (magenta) on the left and right sides of the molecules in figure 2 have been frozen in place to help maintain a reasonable approximation to the structure within DNA. The structures were determined via energy minimization from the same starting geometry in each case. A number of differences exists between the two predicted structures, but the most important is the difference the H-bonding distance between the dCTP and the $(+)-t a-[\mathrm{BP}] \mathrm{G}$. H-bonding is a key parameter determining the interaction of these two components, and it is typically a difficult interaction to account for in molecular modeling. This is true even in ab initio methods, but it is especially true in molecular mechanics simulations. The need to study large biomolecular systems, such as contaminant-DNA adducts, while at the same time accurately reproducing subtle chemical effects, such as H-bonding, is one reason driving the development of hybrid quantum mechanical/molecular mechanical (QM/MM) methods (for example, Dapprich and others, 1999; Shoemaker and others, 1999).

\section{Predictions of Degradation Mechanisms for PAHs}

A major question from this analysis of biochemical reactions that can be related to biogeochemistry is how does BPDE form? Metabolites can form within an organism, but can oxidation of $\mathrm{BaP}$ occur in the environment via microbes or abiotically? The first step in the transformation of BaP to BPDE (fig. 4) is the one-electron oxidation of $\mathrm{BaP}$ to form a radical cation (Cavalieri and Rogan, 1992). Each step of the process outlined in figure 4 could be modeled, but the first step is only considered here. The formation of the radical cation will depend on the ionization potential (IP) of the PAH with a cut-off value of approximately $710 \mathrm{~kJ} / \mathrm{mol}$ (Cavalieri and others, 1983); hence, calculation of IPs is one key to determining whether or not this reaction will proceed.

The IP of a compound can be estimated via calculations on the ground-state of the molecule (that is, Koopman's theorem); however, this method often overestimates IP because it does not take into account the relaxation of electrons around the radical cation that is produced. Consequently, estimates of the IP for $\mathrm{BaP}$ were calculated via two methods: (1) using the energy of the Highest-Occupied Molecular Orbital (HOMO) of the ground-state and (2) by the difference between the ground-state and the radical cation potential energies. The latter should be more accurate.

Examination of table 3 shows that the IPs calculated as the difference between the neutral ground state and the radical cation and those calculated based on the HOMO 

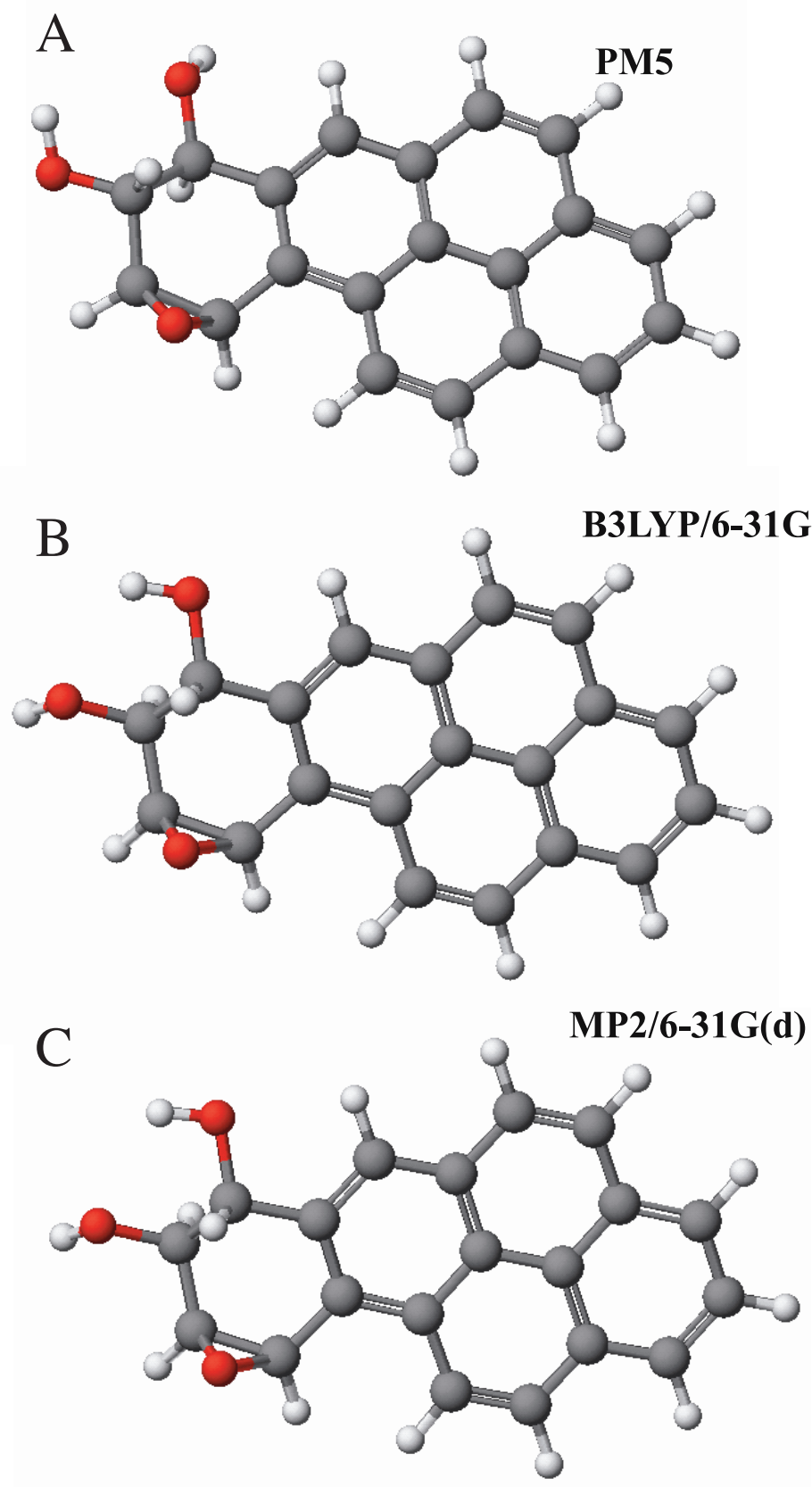

Fig. 3. Structural differences are apparent between the semi-empirical (A) PM5 method and the $a b$ initio (B) B3LYP and (C) MP2 methods for predicting the structure of the stable anti-equatorial conformer of BPDE. 
TABLE 2

Comparison of relative potential energies $(\mathrm{kJ} / \mathrm{mol})$ for four conformations of the benzo[a]pyrene diol epoxide in model aqueous solution

\begin{tabular}{lcccc}
\hline Conformation & COMPASS & PM5 & B3LYP* & B3LYP $^{\S}$ \\
\hline anti-eq & 0 & +14 & +9 & 0 \\
anti-ax & +88 & 0 & +37 & +18 \\
syn-eq & +63 & +14 & 0 & +7 \\
syn-ax & +117 & $<+1$ & +74 & +24 \\
\hline
\end{tabular}

*B3LYP/6-31G(d) gas-phase structure.

§Partially optimized B3LYP/6-31G(d)/IEFPCM structure.

energy level generally have large discrepancies. This error is well known, but it is illustrated here because HOMO-LUMO gaps have been used as indicators of phototoxicity (see below). The former method should be more accurate, but none of the methods presented here do a good job of reproducing the experimental value. Time-dependent density functional theory (TDDFT) may prove to be a reliable method for predicting IPs (Hirata and others, 2003). One cautionary note is that the IP values calculated with both methods in table 3 predict changes if the compound is in aqueous solution $\left(\mathrm{B} 3 \mathrm{LYP}_{(\mathrm{aq})}\right.$ column). This calculation was performed with a polarized continuum method (IEFPCM-Cancès and others, 1997) and may actually underestimate the effect of the solvent because strong H-bonding effects are not explicitly accounted for using this approach.

\section{Calculating Photo-excitations}

A related phenomenon is the photo-excitations of PAHs (see Wernersson, 2003 for a recent review). Although excitation by visible and/or ultraviolet radiation also involves moving an electron out of the ground state configuration, the energy involved in phototoxicity is significantly less than that required to form a radical cation discussed above. The range of UV radiation energy is approximately 300 to 600 $\mathrm{kJ} / \mathrm{mol}$, so the energy available to produce a phototoxic effect reaches a maximum limit just below the energy range where radical cation formation begins to occur (table $3)$. However, this amount of energy is in the range of many bonds in organic contaminants (Schwarzenbach and others, 1993, p. 438).

Previous reports in the literature have used the calculated HOMO-LUMO gaps in the range of $700 \mathrm{~kJ} / \mathrm{mol}$ (Mekenyan and others, 1994) and $850 \mathrm{~kJ} / \mathrm{mol}$ (Dong and others, 2002) to predict phototoxicity effects. However, it is not possible for UV to excite electrons to these types of energy levels, so the correlations between the calculated HOMO-LUMO gap and observed toxicity effects are probably related to the formation of the radical cation and species such as the dihydrol intermediates examined in the section above. Consequently, one cannot invoke a direct photoinduced mechanism based on HOMO-LUMO gap energy greater than $600 \mathrm{~kJ} / \mathrm{mol}$, but indirect effects are possible if the photo-excited state is one step in the formation of the metabolic intermediate.

Electronic transitions are possible, of course, at the lower energies generated in the visible/UV part of the electromagnetic spectrum (visible 175 to $\approx 300 \mathrm{~kJ} / \mathrm{mol}$; Betowski and others, 2002). Indeed, the experimentally measured excitation energies for transferring electrons out of the ground state and forming two unpaired spins $\left({ }^{3} \mathrm{P}^{*}\right)$ or two excited electrons $\left({ }^{1} \mathrm{P}^{*}\right)$ is in the range of 175 to $300 \mathrm{~kJ} / \mathrm{mol}$ (Schmidt, 1977). The carcinogenicity of a suite of PAHs was related to singlet excitations by 

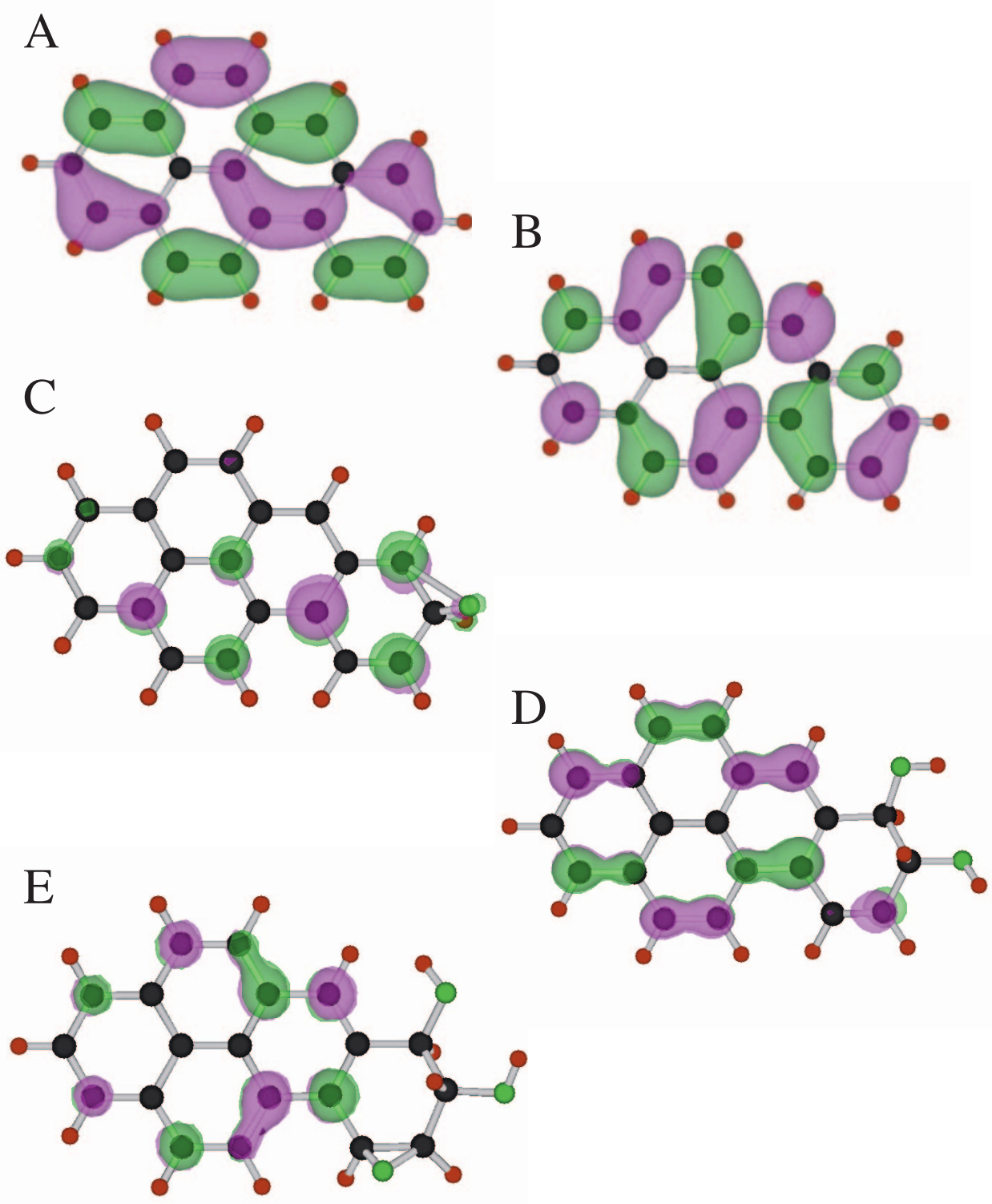

Fig. 4. Representative steps in the photo-oxidation of BaP showing the HOMOs as calculated with the PM3 method in HyperChem 7 (Hypercube, Inc.) starting with (A) the stable ground state which adsorbs radiation to become (B) the excited triplet state. An $\mathrm{O}$ atom may react with the excited $\mathrm{BaP}$ to form $(\mathrm{C})$ the epoxide and then via hydrolysis for the (D) $\mathrm{BaP}$ diol. Another $\mathrm{O}_{2}$ then reacts at the remaining $\pi$-bond of the ring to form (E) BPDE.

Morgan and others (1977), so here the possibility of calculating these excitation energies will be discussed.

A relationship may exist between phototoxicity and IP or HOMO-LUMO gap that explains why the HOMO-LUMO gap can be used as a QSAR even though direct 
TABLE 3

Comparison of estimated IPs $(\mathrm{kJ} / \mathrm{mol})$ for benzo[a]pyrene using various computational methods. Units are different for some methods for convenience because semi-empirical methods have a different reference state than ab initio methods. The former are based on heats of formation from the elements; the latter are based on total energies of forming the molecule from isolated nuclei and electrons. B3LYP and MP2 calculations both used the 6-31G(d) basis set

\begin{tabular}{lccccc}
\hline & PM3 & ZINDO & B3LYP & B3LYP(aq) & MP2 \\
\hline BaP & -3971 & -12278 & $-769.4138 \mathrm{H}$ & $-769.4190 \mathrm{H}$ & $-766.9432 \mathrm{H}$ \\
& $\mathrm{kcal} / \mathrm{mol}$ & $\mathrm{kcal} / \mathrm{mol}$ & & & \\
$\mathrm{BaP}$. & -3792 & -12169 & $-769.1756 \mathrm{H}$ & $-769.2422 \mathrm{H}$ & $-766.6500 \mathrm{H}$ \\
$\mathrm{IP}$ & $\mathrm{kcal} / \mathrm{mol}$ & $\mathrm{kcal} / \mathrm{mol}$ & & & \\
$\mathrm{HOMO}$ & $149 \mathrm{~kJ} / \mathrm{mol}$ & $456 \mathrm{~kJ} / \mathrm{mol}$ & $625 \mathrm{~kJ} / \mathrm{mol}$ & $464 \mathrm{~kJ} / \mathrm{mol}$ & $770 \mathrm{~kJ} / \mathrm{mol}$ \\
\hline
\end{tabular}

$\operatorname{Expt}=698 \mathrm{~kJ} / \mathrm{mol}$.

$*=$ Gas-phase structure.

$\mathrm{H}=1$ Hartree $=2625.5 \mathrm{~kJ} / \mathrm{mol}$.

excitation by sunlight is not a possible mechanism of phototoxicity. This is because there is a strong linear correlation between IP and excitation energies, even though the former are approximately twice the magnitude of the latter (Schmidt, 1977). For example, although calculated HOMO-LUMO gap energies were at least a factor of two larger than the observed triplet excitation energies (Schmidt, 1977), a strong linear correlation existed between the two parameters (Kubicki and others, 1999).

Photo-excitation to the ${ }^{1} \mathrm{P}^{*}$ (rather than forming a radical cation) state may be a step that facilitates oxidation by singlet oxygen for benzo[a]pyrene (Fasnacht and Blough, 2003) whether or not ${ }^{3} \mathrm{P}^{*}$ makes a contribution depends on the lifetime of the more reactive ${ }^{1} \mathrm{P}^{*}$ state (Fasnacht and Blough, 2003). See Schwarzenbach and others (1993, pp. 471-473) for a general description of indirect photolysis of organic compounds. The basic concept is that the excited PAH can excite ${ }^{3} \mathrm{O}_{2}$ to the ${ }^{1} \mathrm{O}_{2}$ state $\left({ }^{3} \mathrm{O}_{2}\right.$ $\rightarrow{ }^{1} \mathrm{O}_{2} \Delta \mathrm{E}=94 \mathrm{~kJ} / \mathrm{mol}$ ) which then begins oxidation of the PAH to the more toxic metabolic intermediate (fig. 4C). Alternatively, hydroxylation of the PAH may be so exothermic that it induces formation of an excited state even when light is not present (Anderson, 1947). Because light does not penetrate inside an organism and metabolic intermediates form anyway (Grover, 1974), this mechanism should be considered a possibility in many instances.

These types of electronic excitations cannot be modeled with classical force fields, so molecular mechanics methods were not included in this component of the study. Semi-empirical (AM1), unrestricted Hartree-Fock (UHF/6-311++G(d,p)), hybrid molecular orbital/density functional theory (B3LYP/6-311++G $(\mathrm{d}, \mathrm{p})$ ), CI-singles (CIS/ 6-311G(d,p); see Gittins and others, 1996; Goodpaster and others, 1998; and Betowski and others, 2002 for previous calculations on benzo $[a]$ pyrene and other PAHs), and TDDFT (Stratmann and others, 1998; Hirata and others, 2003) methods were employed to calculate the energy differences between the ground state for benzo$[a]$ pyrene and the excited triplet and singlet states. Excitation energies estimated by each method are listed in table 4. The PM3, CIS, and TDDFT calculations predict vertical excitation energies (that is, the energy to move an electron from the ground state structure into the excited state). The HF and B3LYP values presented are for adiabatic excitation energies (that is, the energy difference between the ground state and excited state in their respective energy minima). Because the molecular structure 
TABLE 4

Comparison of estimated triplet and singlet excitation energies $(\mathrm{kJ} / \mathrm{mol})$ for benzo[a]pyrene using various computational methods

\begin{tabular}{lcccccc}
\hline & PM3 & HF & B3LYP & CIS1** & CIS2 $^{\dagger}$ & TDDFT $^{\ddagger}$ \\
\hline${ }^{3} \mathrm{P}^{*}$ & +190 & +46 & +172 & +205 & +179 & +176 \\
Aqueous & +190 & ---- & ----- & ----- & ---- & ----- \\
${ }^{1} \mathrm{P}^{*}$ & +312 & ----- & ----- & +413 & +388 & +304 \\
Aqueous & +311 & ----- & ----- & ----- & ----- & ---- \\
\hline
\end{tabular}

Experiment $-{ }^{3} \mathrm{P}^{*}=+177 \mathrm{~kJ} / \mathrm{mol} ;{ }^{1} \mathrm{P}^{*}=297 \mathrm{~kJ} / \mathrm{mol}$ (Morgan and others, 1977)

${ }^{1} \mathrm{P}^{*} \approx 310$ to $325 \mathrm{~kJ} / \mathrm{mol}$ (Schmidt, 1977).

**CIS/6-311G(d,p) calculations in HF/6-311G(d,p) structures by Betowski and others (2002).

†CIS/6-311G(d,p) calculations optimized with the B3LYP/6-311++G(d,p) structure.

${ }_{+} \mathrm{TD} / \mathrm{B} 3 \mathrm{LYP} / 6-311 \mathrm{G}(\mathrm{d}, \mathrm{p})$ vertical excitation in the B3LYP/6-311+ $+\mathrm{G}(\mathrm{d}, \mathrm{p})$ structure MP2/6$311 \mathrm{G}(\mathrm{d}, \mathrm{p})=-766.9432 \mathrm{H}(\mathrm{H}=$ Hartree $/$ molecule $=2625.5 \mathrm{~kJ} / \mathrm{mol})$.

is expected to relax rapidly compared with the lifetime of the excited state, the latter should be theoretically more accurate compared to observation. The most reliable of the above methods is likely to be TDDFT (Cramer, 2002). See Cramer (2002) for a discussion.

Except for the Hartree-Fock method, all the calculations do a reasonable job of reproducing the triplet experimental excitation energies. The semi-empirical PM3 method (Stewart, 1989) is the most computationally efficient of these and can run within seconds on today's PCs. Consequently, a huge number of PAHs can be screened for carcinogenicity before performing expensive in vivo experiments.

The most accurate of the methods is the TDDFT, and although computationally more expensive than semi-empirical methods, it is much more efficient than MP2 methods. The structure for the TDDFT calculations was that of benza $[a]$ pyrene in the ground state using the B3LYP/6-311++G(d,p) method (that is, a vertical excitation was calculated). The B3LYP/6-311++G(d,p) method appears to give a fairly accurate structure of benzo $[a]$ pyrene because not only does the TDDFT method give an accurate prediction compared to experiment, but the CIS/6-311G(d,p) calculations become more accurate relevant to experiment compared to the CIS/6-311G $(\mathrm{d}, \mathrm{p})$ calculations based on the HF/6-311G(d,p) structure (see CIS1 versus CIS2 in table 4).

An important point to note is that the aqueous excitation energy is not significantly different than the gas-phase value. This prediction is consistent with the observation of Schmidt (1977) that photoelectron spectra of PAHs do not change more than $10 \mathrm{~kJ} / \mathrm{mol}$ between the gas and aqueous phases. The reason for this is that water does not strongly interact with the electrons of these hydrophobic compounds. If this holds true for more compounds, it greatly simplifies the process of calculating excitation energies. One must be cautious, however, and realize that substituent effects may change this behavior if the modifications make the compound more hydrophilic (for example, if polar functional groups are added).

Morgan and others (1977) observed that PAH compounds were approximately 23 times more likely to be carcinogenic if their singlet excitation energies fell within the range 297 to $310 \mathrm{~kJ} / \mathrm{mol}$. However, there was no significant correlation between carcinogenicity and the triplet excitation energy. Consequently, effort should focus on computing singlet excitation energies and possible reactions that may occur from this state. For example, as mentioned above, if figure $4 \mathrm{~B}$ is in a ${ }^{1} \mathrm{P}^{*}$ state, then the addition of an $\mathrm{O}$ atom to form the epoxide is facilitated because the ${ }^{3} \mathrm{O}_{2}$ molecule can readily be excited to ${ }^{1} \mathrm{O}_{2}$ then dissociate to add an $\mathrm{O}$ to the $\mathrm{BaP}$. This is a key point, because if we 
want to model the photo- or biodegradation process, then we must model the molecular and electronic structures in the excited states. Calculating vertical transitions with methods such as PM3 or TDDFT will be useful for selecting which compounds will be excited, but these vertical transition calculations cannot be used directly to model the reaction mechanisms associated with oxidation.

If radical cations are already formed, then their electronic transitions will be lower in energy compared to the ground state and readily excited by visible light. Hirata and others (2003) calculated a value of $+86 \mathrm{~kJ} / \mathrm{mol}$ for this $\pi-\pi^{*}$ transition using TDDFT as compared to the experimental value of $+92 \mathrm{~kJ} / \mathrm{mol}$ (Shida, 1988). The maximum experimental value for an electronic transition in the radical cation of benzo $[a]$ pyrene is less than $210 \mathrm{~kJ} / \mathrm{mol}$ (Khan, 1989). However, this requires that the radical cation form by some other mechanism before the phototoxicity effect can occur. This step would have the highest activation energy in the overall process and would therefore be the rate-limiting step of interest, not the photo-excitation.

\section{Modeling Interactions of Organic Compounds with Soot and Mineral Surfaces}

Studies such as those by McGroddy and Farrington (1995) and Gustafsson and others (1997) have demonstrated that interactions of PAHs with sediments can greatly extend the persistence of these pollutants in the environment. These associations may begin with formation of the soot particle in the atmosphere (Dobbins and others, 1995) and affect the photochemistry of the PAH in the atmosphere (Behymer and Hites, 1985; Tancell and others, 1995). Experimental work has shown that PAH/soot partition coefficients, $\mathrm{K}_{\mathrm{sc}}$, can be significantly higher than "normal" $\mathrm{K}_{\mathrm{oc}}$ values (Bucheli and Gustafsson, 2000). Determining interaction mechanisms in these systems can be problematic because of the similarity between the soot and PAH (that is, both are highly aromatic carbonaceous materials). Furthermore, conducting equilibrium partitioning experiments can be expensive and time-consuming in the laboratory (on the order of months; Bucheli and Gustafsson, 2000).

Molecular modeling techniques can be used to address both of these problems. First, details of the molecular structure are always known in the simulations, and it is trivial to distinguish different molecules in the virtual realm (fig. 5). Hence, interaction mechanisms can be readily obtained from the molecular simulation as long as we verify that the simulations are accurate compared to experimental data. Second, computational methods can be developed that allow for rapid (on the order of 1 hour) estimation of the $\mathrm{K}_{\mathrm{sc}}$ values. Screening times can be decreased dramatically as more computer power is used, so time and resource savings can be even larger.

Another advantage of the modeling approach is that some experimental limitations are lifted. For instance, compounds such as benzene have high volatilities, which make them difficult to work with in the laboratory when one is attempting to accurately derive aqueous/soot partitioning behavior. If a significant amount of the compound evaporates, then analytical accuracy decreases. On the other end of the spectrum, aqueous solubilities of some compounds may be so low that it is difficult to accurately measure how much is in solution at the end of a partitioning experiment. Neither of these real world issues is a problem for computer modeling of interaction energies.

Classical molecular simulations were performed in order to generate possible configurations for $\mathrm{BaP}$ sorbed onto soot (fig. 5). Based on a model for hexane soot derived by Smith and coworkers (Akhter and others, 1985; Smith and Chughtai, 1995), the formation of soot in the presence of $\mathrm{BaP}$ was modeled using the COMPASS force field (Sun, 1998) in Cerius ${ }^{2}$ (Accelrys, Inc.). The choice of model system is the most important aspect of generating useful simulation results, so selecting a model soot structure based on extensive experimental data is critical. Equal in importance is the selection of a force field that adequately describes bonded and longer range interactions in the system of interest. The COMPASS (Sun, 1998) force field was derived by 


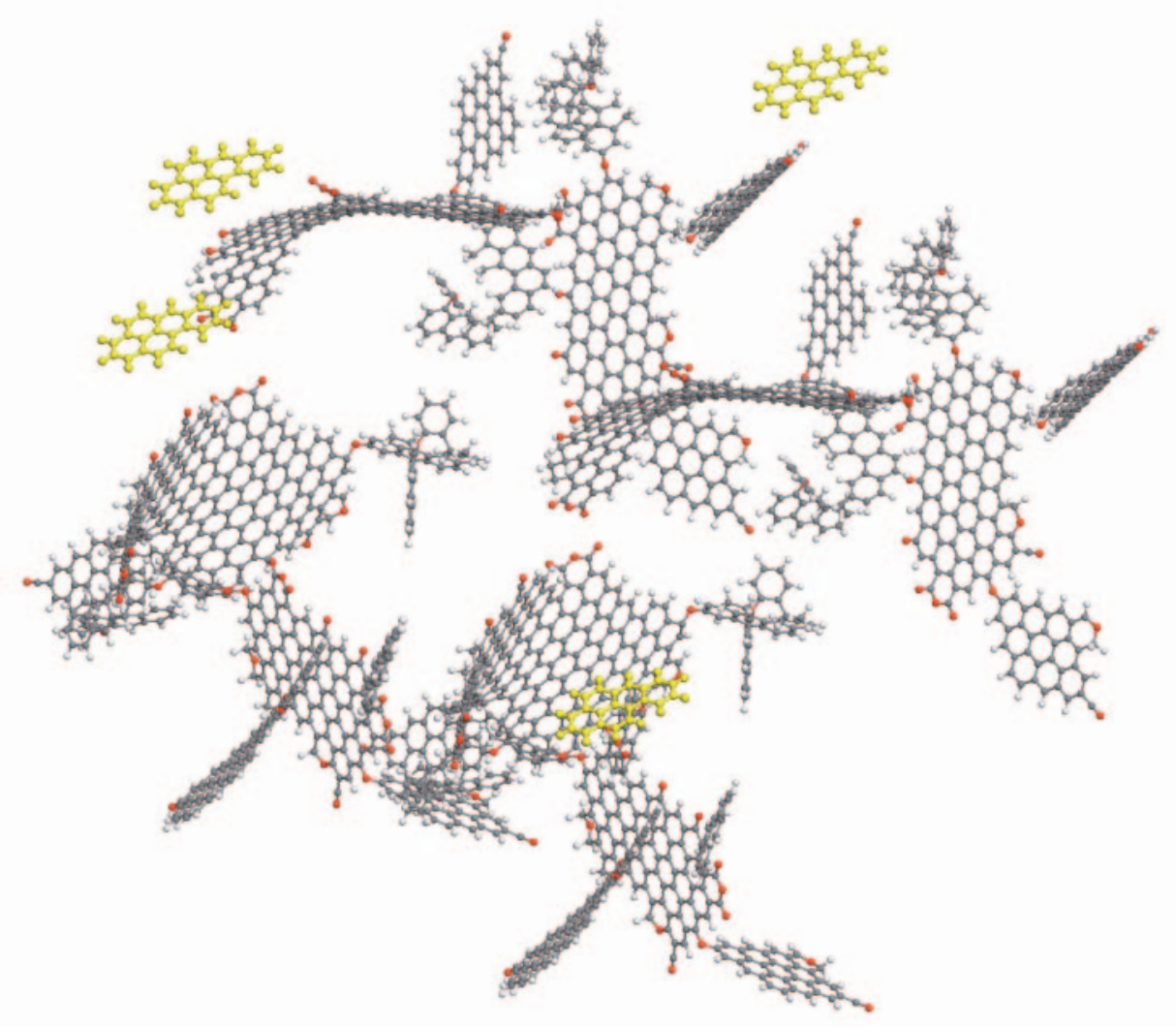

Fig. 5. (A) Model structure of a hexane soot taken from Akhter and others (1985) with four BaP molecules added in yellow. This structure represents an energy minimization procedure carried out in Cerius $^{2}$ (Accelrys, Inc.) using the COMPASS force field (Sun, 1998).

fitting parameters to ab initio results and experimental data on condensed systems, so it is capable of producing realistic results for PAHs and soot (Kubicki, 2000).

The model system results after 100,000 times steps (100 ps) of molecular dynamics simulation shows two types of $\mathrm{BaP}$ interactions with the hexane soot. First, $\mathrm{BaP}$ is adsorbed onto the aromatic surfaces of the soot nanoparticle $(\approx 5 \mathrm{~nm}$ diameter). This $\mathrm{BaP}$ would be available to partition back into the water according to the $\mathrm{K}_{\mathrm{sc}}$. If a PAH were adsorbed onto a soot particle in a soil or sediment from the pore water, then this is the most likely mechanism of interaction. Second, BaP can be absorbed within the soot particle. Because the soot was modeled from an initially open state based on PAH-like fragments, this simulation represents what may occur as a soot particle condenses out of a flame (Dobbins and others, 1995; Reddy and others, 2002). In this case, the BaP will be more strongly sequestered and may never even see water in the hydrophobic micro-domain within the soot particle. Actual soot particles are on the order of $20 \mathrm{~nm}$ to $1 \mu \mathrm{m}$ (Palotas and others, 1996), so long-term sequestration and near zero bioavailability are likely results of this second type of interaction.

In order to help verify the results of these classical simulations, ab initio calculations were performed on sub-systems derived from the larger scale simulations. Pairs of PAHs with a model aromatic soot fragment (in actuality, the PAH coronene) were 


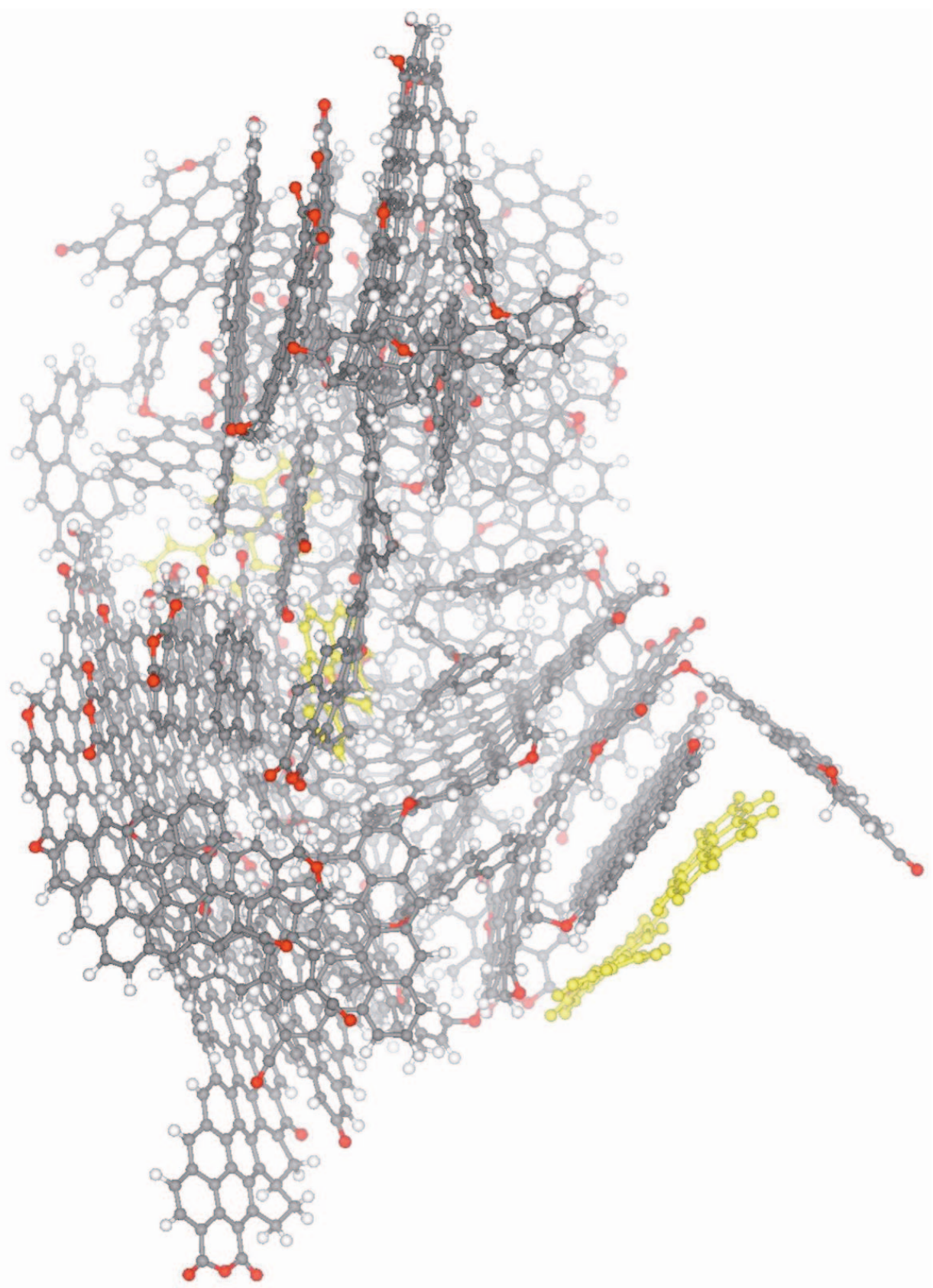

Fig. 5. (B) The same system illustrated in figure $5 \mathrm{~A}$ after $100 \mathrm{ps}$ MD simulation at $300 \mathrm{~K}$ within an N-V-T ensemble. The model soot particle has condensed to maximize $\pi-\pi$ interactions between soot fragments, and the $\mathrm{BaP}$ molecules are strongly associated both outside and inside the model soot.

generated using energy minimizations and the COMPASS force field. The adsorption energies, $\Delta \mathrm{E}_{\text {ads }}$, were calculated within Gaussian 03 (Frisch and others, 2003) using the MP2/6-31G(d) method. The $\Delta \mathrm{E}_{\text {ads }}$ was considered to be the difference between the 


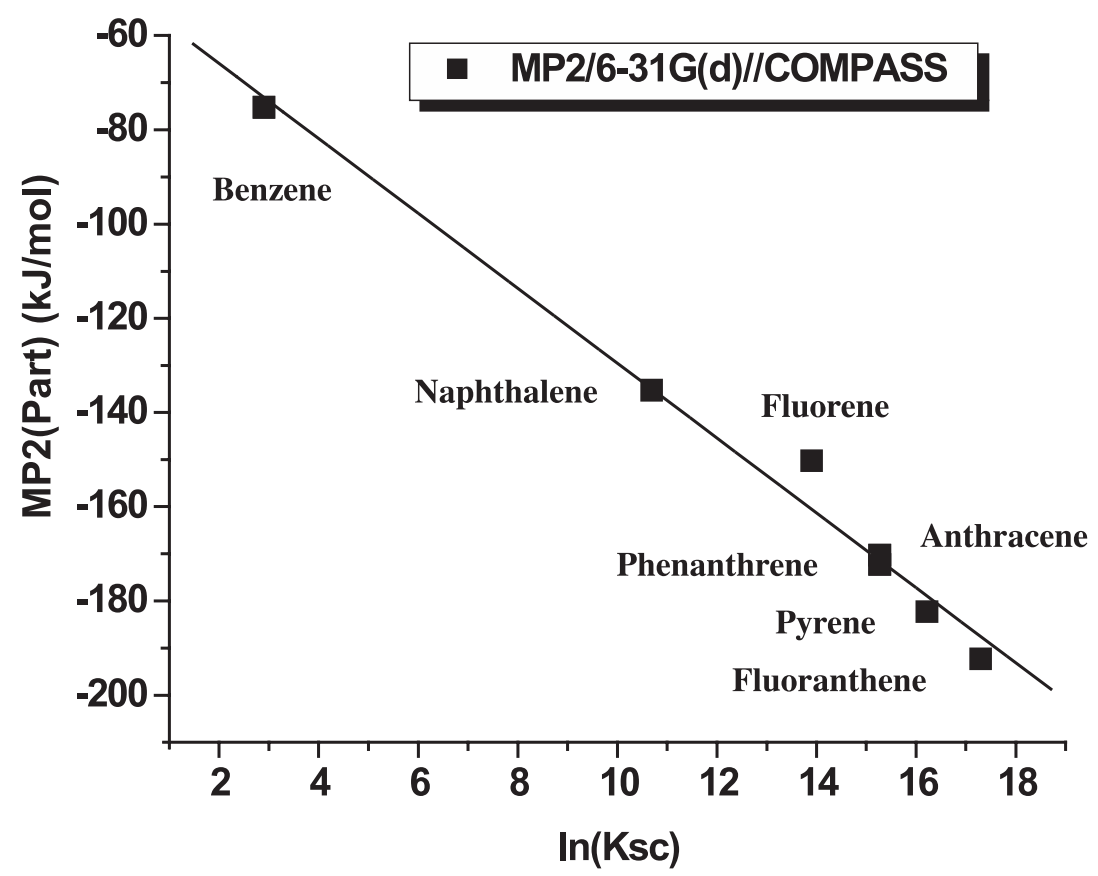

Fig. 6. Correlation of calculated soot-water partitioning energies for benzene and a suite of PAHs with the observed (Bucheli and Gustafsson, 2000) soot-water partition coefficients ( $\operatorname{lnK}_{\mathrm{sc}}$ ) for naphthalene, fluorene, phenanthrene and pyrene. The $\operatorname{lnK}_{\mathrm{sc}}$ values for benzene, anthracene and fluoranthene were predicted based on the correlation of the above four compounds with experiment. Energy differences were calculated using the MP2/6-31G(d) method in Gaussian 03 (Frisch and others, 2003) based on structures derived from the COMPASS force field using Cerius ${ }^{2}$ (Accelrys, Inc.).

energy of the PAH-soot pair and the isolated PAH and soot molecules. In this manner, just the interaction energy is estimated. Previous simulations suggested that $\pi-\pi$ interactions controlled adsorption of PAHs onto soot (Marzec, 2000; Kubicki, 2000), so more accurate $a b$ initio calculations of the interaction energies in this configuration should correlate with the observed $\mathrm{K}_{\mathrm{sc}}$ values if the predicted mechanism were accurate.

Figure 6 is a correlation between the $\Delta \mathrm{E}_{\mathrm{ads}}$ of four PAHs (naphthalene, fluorene, phenanthrene, and pyrene) and the observed $\log \left(\mathrm{K}_{\mathrm{sc}}\right)$ values (Bucheli and Gustafsson, 2000). The fact that the correlation is excellent suggests that the mechanism is correct and that the MP2/6-31G(d) method does an adequate job of representing the PAH-soot $\pi-\pi$ interactions. Three other $\log \left(\mathrm{K}_{\mathrm{sc}}\right)$ values are predicted for benzene, anthracene, and fluoranthene. These predictions could be tested by experiments similar to those presented in Bucheli and Gustafsson (2000). Relatively strong $\pi-\pi$ interactions between PAHs and soot or aromatic components of NOM are likely to be the reason for the correlation between persistence and the "hardness" of NOM (Huang and Weber, 1997).

\section{Chemistry of Metabolic Intermediates}

Transformations of organic contaminants into metabolic intermediates can change the original chemical properties a great deal. One possibility is that the metabolic intermediate can be incorporated into the humic matter in a soil (Richnow and others, 1993). Partial oxidation of BaP can form catecholate species (fig. 7A-see Penning, 

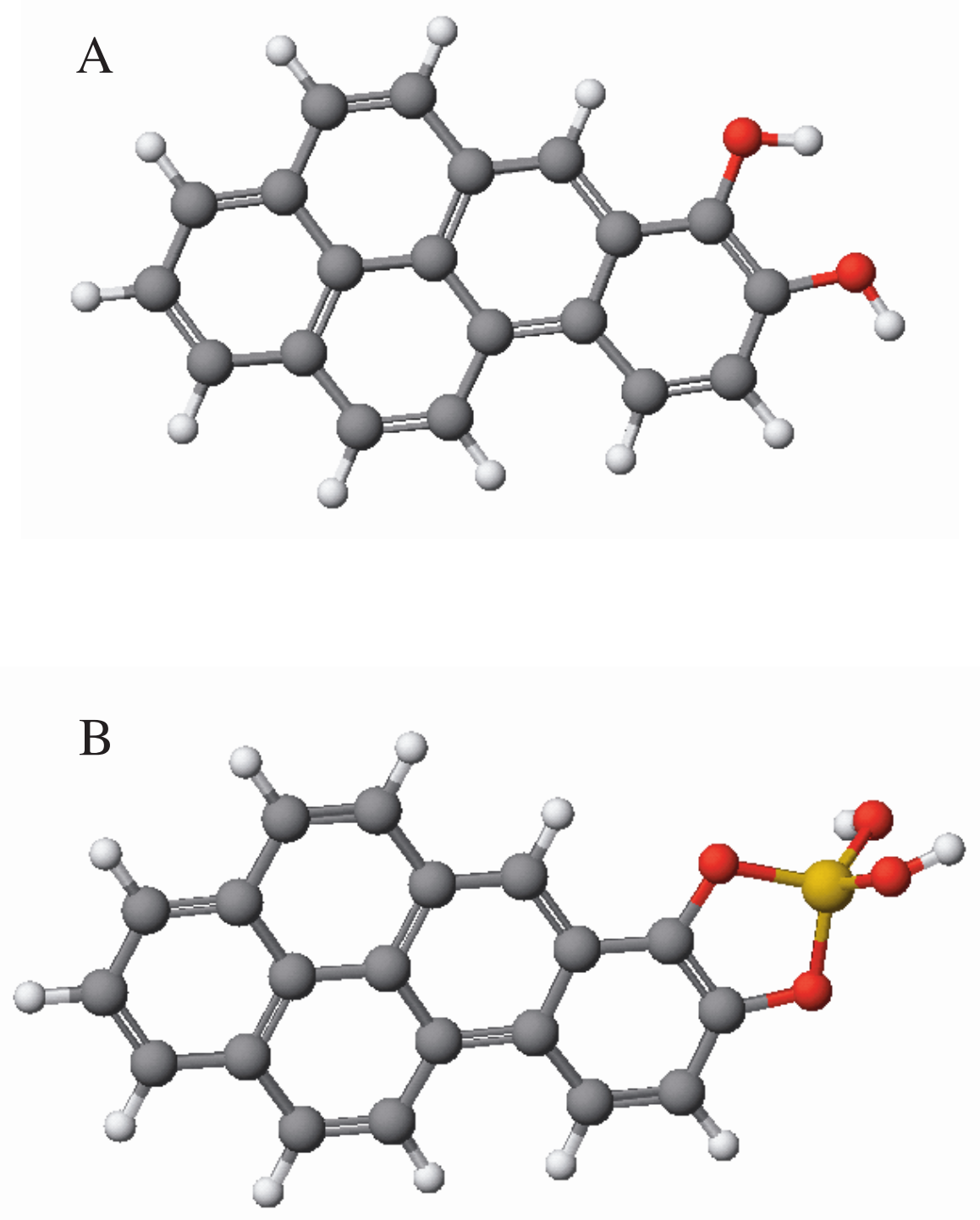

Fig. 7. (A) Model of BaP catecholate complex which was used to estimate the dipole moment of this possible breakdown product of Bap. (B) Energy minimized structure of a BaP catecholate-Si complex that could form in solution or on mineral surfaces as the breakdown product of the BaP becomes more reactive. Both models generated using B3LYP/6-31G(d) in Gaussian 03 (Frisch and others, 2003).

1993 for a review). Such a transformation is common among PAHs and will lead to a dramatic decrease in the octanol-water partitioning coefficient, $\mathrm{K}_{\mathrm{ow}}$, which controls the transport in aqueous solutions and bioaccumulation of compounds. For example, the calculated dipole moment of $\mathrm{BaP}$ is approximately 0 in this study whereas that of the catecholate derivative is $\approx 2.7$ Debye (B3LYP/6-31G(d) structure and electron density). Consequently, the aqueous solubility of the metabolic intermediate will increase, transport of the new compound will be sped up, and the toxicity may change for the better or worse depending on the compound. 
A systematic study should be conducted to derive parameters such as the dipole moments and hydrophobic surface areas of hydrophobic organic contaminants and their metabolic intermediates for comparison with experiment aqueous solubilites, $\mathrm{K}_{\mathrm{ow}} \mathrm{s}$, and toxicities. Such a database would allow rapid prediction of environmental changes induced by partial biodegradation of organic pollutants.

\section{BaP_Cat-Si}

Another issue with forming metabolic intermediates, such as the BaP catecholate species in figure $7 \mathrm{~B}$, is that the new compounds may be able to complex with aqueous and mineral surface species. For instance, catechol is known to strongly complex with $\mathrm{Si}^{4+}$ (Iler, 1979) which is nearly ubiquitous in natural waters, soils and sediments because $\mathrm{Si}$ is the most abundant cation in the Earth's crust. Molecular orbital calculations demonstrate an example of a potential BaP catecholate-Si complex (fig. 7B). Such reactions may occur in solution or on silicate mineral surfaces; thus, the mobility and toxicity of the metabolic intermediate will be affected. Furthermore, attempts to completely mineralize the original compound may be frustrated in the field, if the complex is incapable of being metabolized by microorganisms.

SUMMARY AND FUTURE DIRECTIONS

Any technique has limitations and disadvantages, but computational chemistry enjoys a rare position in that computer speed is growing at a rapid rate. Consequently, even without the progress in algorithms and software that is occurring simultaneously, the realm of possible studies expands regularly and higher levels of accuracy can be achieved with equal or less investment of time and money. Computational chemistry works best in complex systems when there is close collaboration between the experimentalists and modelers. Often, too many simplifications are included in a model system and the essence of the chemical problem is lost. In addition, we are never likely to be able to predict all the possible bio- and geochemistry that may occur in the environment, so field and laboratory studies must help us select which problems to work on.

The number of problems in biogeochemistry that can be approached with computational techniques is almost limitless, so this should be an area of growth for the foreseeable future. Examination of excited state chemistry, metabolic intermediates, reaction mechanisms and trace compound interactions will be a few areas that deserve special attention because they are important and have been relatively neglected. Systems where a trace concentration of a reactive species controls reaction kinetics are commonly problematic to study experimentally because these compounds are difficult to identify and detect with spectroscopic methods. However, if reaction mechanisms can be constrained by wet chemical studies and spectroscopy, then computational chemistry may be able to help fill in the gaps of our understanding in many instances in the future.

\section{ACKNOWLEDGMENTS}

This work was supported by the National Science Foundation grants "Molecular level analysis of macromolecule-surface interactions in bacterial adhesion" and "Stony Brook-BNL collaboration to establish a Center for Environmental Molecular Sciences (CEMS)." Computation was supported in part by the Materials Simulation Center, a Penn-State MRSEC and MRI facility.

\section{REFERENCES}

Akhter, M. S., Chughtai, A. R., and Smith, D. M., 1985, The structure of hexane soot I: Spectroscopic studies: Applied Spectroscopy, v. 39, p. 143-153.

Alexander, M., 1994, Biodegradation and bioremediation: San Diego, Academic Press, 302 p. 
1995, How toxic are toxic chemicals in soil?: Environmental Science and Technology, v. 29, p. 27132717.

Anderson, W., 1947, Physico-chemical aspects of chemical carcinogens: Nature, v. 160, p. 892-895.

Becke, A. D., 1993, Density-functional thermochemistry .3. The role of exact exchange: Journal of Physical Chemistry, v. 98 , p. $5648-5652$.

Behymer, T. D., and Hites, R. A., 1985, Photolysis of polycyclic aromatic hydrocarbons adsorbed on simulated atmospheric particulates: Environmental Science and Technology, v. 19, p. 1004-1006.

Betowski, L. D., Enlow, M., and Riddick, L., The phototoxicity of polycyclic aromatic hydrocarbons: A theoretical study of excited states and correlation to experiment: Computers and Chemistry, v. 26, p. 371-377.

Beyer, A., Wania, F., Gouin, T., Mackay, D., and Matthies, M., 2002, Selecting internally consistent physicochemical properties of organic compounds: Environmental Toxicology and Chemistry, v. 21, p. 941-953.

Boudreau, B. P., 1999, A theoretical investigation of the organic carbon-microbial biomass relation in muddy sediments: Aquatic Microbiological Ecology, v. 17, p. 181-189.

Brown, K. W., Little, S. B., and Rabinowitz, J. R., 2002, Benzo[a]pyrene and benz[c]phenanthrene: The effect of structure on the binding of water molecules to the diol epoxides: Chemical Research in Toxicology, v. 15, p. 1069-1079.

Bucheli, T. D., and Gustafsson, O., 2000, Quantification of the soot-water distribution coefficient of PAHs provides mechanistic basis for enhanced sorption observations: Environmental Science and Technology, v. 34, p. 5144-5151.

2003, Soot sorption of non-ortho- and ortho-substituted PCBs: Chemosphere, v. 53, p. 515-522.

Cancès, E., Mennucci, B., and Tomasi, J., 1997, A new integral equation formalism for the polarizable continuum model: Theoretical background and applications to isotropic and anisotropic dielectrics: Journal of Chemical Physics, v. 107, p. 3032-3041.

Cavalieri, E. L., and Rogan, E. G., 1992, The approach to understanding aromatic hydrocarbon carcinogenesis. The central role of radical cations in metabolic activation: Pharmacological. Therapeutics, v. 55, p. 183-199.

Cavalieri, E. L., Rogan, E., Roth, R. W., Saugier, R. K., and Hakam, A., 1983, The relationship between ionization potential and horseradish peroxidase/hydrogen peroxide-catalyzed binding of aromatic hydrocarbons to DNA: Chemical Biological Interactions, v. 47, p. 87-109.

Cheng, A. L., and Merz, K. M., 2003, Prediction of aqueous solubility of a diverse set of compounds using quantitative structure-property relationships: Journal Medicinal Chemistry, v. 46, p. 3572-3580.

Cramer, C. J., 2002, Essentials of Computational Chemistry: Theories and Models: West Sussex, England, Wiley, $542 \mathrm{p}$

Cygan, R. T., 2001, Molecular modeling in mineralogy and geochemistry, in Cygan, R. T., and Kubicki, J. D. editors, Molecular modeling theory: Applications in the Geosciences: Reviews in Mineralogy, v. 42, p. 1-35.

Cygan, R. T., and Kubicki, J. D., 2001, Molecular Modeling Theory: Applications in the Geosciences: Reviews in Mineralogy, v. 42, 531 p.

Dapprich, S., Komaromi, I., Byun, K. S., Morokuma, K., and Frisch, M. J., 1999, A new ONIOM implementation in Gaussian 98. Part I. The calculation of energies, gradients, vibrational frequencies and electric field derivatives: Journal of Molecular Structure -Theochem, v. 461-462, p. 1-21.

Di Toro, D. M., Allen, H. E., Bergman, H. L., Meyer, J. S., Paquin, P. R., and Santore, R. C., 2001, Biotic ligand model of the acute toxicity of metals. 1. Technical basis: Environmental Toxicology and Chemistry, v. 20, p. 2383-2396.

Dobbins, R. A., Fletcher, R. A., and Lu, W., 1995, Laser microprobe analysis of soot precursor particles and carbonaceous soot: Combustion and Flame, v. 100, p. 301-309.

Dong, S., Fu, P. P., Shirsat, R. N., Hwang, H. M., Leszczynski, J., and Yu, H., 2002, UVA light-induced DNA cleavage by isomeric methylbenz[a]anthracenes: Chemical Research in Toxicology, v. 15, p. 400-407.

Farrell, J., and Reinhard, M., 1994, Desorption of halogenated organics from model solids, sediments, and soil under unsaturated conditions. 1. Isotherms: Environmental Science and Technology, v. 28, p. 53-62.

Farrell, J., Luo, J., Blowers, P., and Curry, J., 2002, Experimental and molecular mechanics and ab initio investigation of activated adsorption and desorption of trichloroethylene in mineral micropores: Environmental Science and Technology, v. 36, p. 1524-1531.

Fasnacht, M. P., and Blough, N. V., 2003, Kinetic analysis of the photodegradation of polycyclic aromatic hydrocarbons in aqueous solution: Aquatic Science, v. 65, p. 353-358.

Foresman, J. B., and Frisch, A. E., 1997, Exploring chemistry with electronic structure methods, $2^{\text {nd }}$ edition: Pittsburgh, Pennsylvania, Gaussian, 296 p.

Foresman, J. B., Headgordon, M., Pople, J. A., and Frisch, M. J., 1992, Toward a systematic molecular-orbital theory for excited states: Journal of Physical Chemistry, v. 96, p. 135-149.

Frenkel, D., and Smit, B., 2002, Understanding Molecular Simulation: From Algorithms to Applications: San Diego, Academic Press, 638 p.

Frisch, M. J., and others, 2003, Gaussian 03 (Revision B.05): Pittsburg, Pennsylvania, Gaussian, Inc.

Gittins, C. M., Rohlfing, E. A., and Rohlfing, C. M., 1996, Experimental and theoretical characterization of the S-1-S-0 transition of benzo[a] pyrene: Journal of Chemical Physics, v. 105, p. 7323-7335.

Goodpaster, J. V., Harrison, J. F., and McGuffin, V. L., 1998, Ab initio study of polycyclic aromatic hydrocarbons in their ground and excited states: Journal of Physical Chemistry A, v. 102, p. 3372-3381.

Govers, H. A. J., Krop, H. B., Parsons, J. R., Tambach, T., and Kubicki, J. D., 2002, Dissolved organic carbon-contaminant interaction descriptors found by 3D force field calculations: SAR and QSAR in Environmental Research, v. 13, p. 271-280. 
Grimmer, G., 1993, Relevance of polycyclic aromatic hydrocarbons as environmental carcinogens, in Garrigues, P., and Lamotte, M., editors, Proceedings $13^{\text {th }}$ International Symposium Polynuclear Aromatic Hydrocarbons: Langhorne, Pennyslvania, Gordon and Breach Science Publishers, p. 31-41.

Grover, P. L., 1974, K-Region epoxides of polycylic hydrocarbons formation and further metabolism by rat-lung preparations: Biochemical Pharmacology, v. 23, p. 333-343.

Gustafsson, O., Haghseta, F., Chan, C., MacFarlane, J., and Gschwend, P. M., 1997, Quantification of the dilute sedimentary soot phase: Implications for PAH speciation and bioavailability: Environmental Science and Technology, v. 31, p. 203-209.

Harvey, R., 1991, Polycyclic aromatic hydrocarbons: chemistry and carcinogenicity: Cambridge, Cambridge University Press, $396 \mathrm{p}$.

He, L. N., Jurs, P. C., Custer, L. L., Durham, S. K., and Pearl, G. M., 2003, Predicting the genotoxicity of polycyclic aromatic compounds from molecular structure with different classifiers: Chemical Research in Toxicology, v. 16, p. 1567-1580.

Hehre, W. J., Ditchfield, R., and Pople, J. A., 1972, Self-consistent molecular orbital methods. XII. Further extension of Gaussian-type basis sets for use in molecular orbital studies of organic molecules: Journal of Chemical Physics, v. 56, p. 2257-2261.

Hirata, S., Head-Gordon, M., Szczepanski, J., and Vala, M., 2003, Time-dependent density functional study of the electronic excited states of polycyclic aromatic hydrocarbon radical ions: Journal of Physical Chemistry, v. 107, p. 4940-4951.

Huang, W., and Weber, W. J., 1997, A distributed reactivity model for sorption by soils and sediments. 10. Relationships between desorption hysteresis and the diagenetic profiles of organic domains II and III: Environmental Science and Technology, v. 31, p. 2562-2569.

Hunter, K. S., Wang, Y. F., and Van Cappellen, P., 1998, Kinetic modeling of microbially-driven redox chemistry of subsurface environments: coupling transport, microbial metabolism and geochemistry: Journal of Hydrology, v. 209, p. 53-80.

Iler, R. K., 1979, The Chemistry of Silica: New York, Wiley, 866 p.

Khan, Z., 1989, Electronic spectra of radical cations and their correlation with photoelectron spectra $=\mathrm{v}$. Pyrenes: Spectrochimica Acta, v. 45A, p. 253-270.

Kosian, P. A., Makynen, E. A., Monson, P. D., Mount, D.R., Spacie, A., Mekenyan, O. G., and Ankley, G. T., 1998, Application of toxicity-based fractionation techniques and structure-activity relationship models for the identification of phototoxic polycyclic aromatic hydrocarbons in sediment pore water: Environmental Toxicology and Chemistry, v. 17, p. 1021-1033.

Krishnan, R., Binkley, J. S., Seeger, R., and Pople, J. A., 1980, Self-consistent molecular orbital methods. XX. A basis set for correlated wave functions: Journal of Chemical Physics, v. 72, p. 650-654.

Kubicki, J. D., 2000, Molecular mechanics and quantum mechanical modeling of hexane soot structure and interactions with pyrene: Geochemical Transactions, v. 7, DOI: 10.1039/b004601i.

2002, Ab initio calculations of PAH-soot interaction energies for use in predicting partitioning onto soot: Salt Lake City, Utah, SETAC National Meeting.

- 2003, Ab initio calculations of structures of polychlorinated biphenyls for use in predicting partitioning onto soot: Austin, Texas, SETAC National Meeting.

Kubicki, J. D., Blake, G. A., and Apitz, S. E., 1999, Molecular models of benzene and selected PAHs in the gas, aqueous, and adsorbed states: Environmental Toxicology and Chemistry, v. 18, p. 1656-1662.

Lee, C. T., Yang, W. T., and Parr, R. G., 1988, Development of the Colle-Salvetti correlation energy formula into a functional of the electron density: Physical Review B, v. 37, p. 785.

Lepre, C. A., Peng, J., Fejzo, J., Abdul-Manan, N., Pocas, J., Jacobs, M., Xie, X. L., and Moore, J. M., 2002, Applications of SHAPES screening in drug discovery: Combinatorial Chemistry and High Throughput Screening, v. 5, p. 583-590.

Little, S. B., Rabinowitz, J. R., Wei, P., and Yang, W., 1999, A comparison of calculated and experimental geometries for crowded polycyclic aromatic hydrocarbons and their metabolites: Polycyclic Aromatic Compounds, v. 14, p. 53-61.

Long, S. C., and Aelion, C. M., 1999, Metabolite formation and toxicity measurements in evaluating bioremediation of a jet-fuel-contaminated aquifer: Applied Biochemistry and Biotechnology, v. 76, p. $79-97$.

Luo, J., and Farrell, J., 2003, Examination of hydrophohic contaminant adsorption in mineral micropores with grand canonical Monte Carlo simulations: Environmental Science and Technology, v. 37, p. 17751782 .

Luthy, R. G., Aiken, G. R., Brusseau, M. L., Cunningham, S. D., Gschwend, P. M., Pignatello, J. J., Reinhard, M., Traina, S. J., Weber, W. J., Jr., and Westall, J. C., 1997, Sequestration of hydrophobic organic contaminants by geosorbents: Environmental Science and Technology, v. 31, p. 3341-3347.

Marzec, A., 2000, Intermolecular interactions of aromatic hydrocarbons in carbonaceous materials-A molecular and quantum mechanics: Carbon, v. 38, p. 1863-1871.

McCarthy, J. F., Jimenez, B. D., and Barbee, T., 1985, Effect of dissolved humic material on accumulation of polycyclic aromatic hydrocarbons: Structure-activity relationships: Aquatic Toxicology, v. 7, p. 15-24.

McGroddy, S. E., and Farrington, J. W., 1995, Sediment porewater partitioning of polycyclic aromatic hydrocarbons in three cores from Boston Harbor, Massachusetts: Environmental Science and Technology, v. 29, p. 1542-1550.

McLachlan, M. S., Czub, G., and Wania, F., 2002, The influence of vertical sorbed phase transport on the fate of organic chemicals in surface soils: Environmental Science and Technology, v. 36, p. 4860-4867.

McLean, A. D., and Chandler, G. S., 1980, Contracted basis sets for molecular calculations. I. Second row atoms, $\mathrm{Z}=11-18$ : Journal of Chemical Physics, v. 72, p. 5639-5648.

Mekenyan, O. G., Ankley, G. T., Veith, G. D., and Call, D. J., 1994, QSARs for photoinduced toxicity: I. Acute lethality of polycyclic aromatic hydrocarbons to Daphnia magna: Chemosphere, v. 28, p. 567-582. 
Meile, C., Tuncay, K., and Van Cappellen, P., 2003, Explicit representation of spatial heterogeneity in reactive transport models: application to bioirrigated sediments: Journal of Geochemical Exploration, v. 78, p. 231-234 Sp. Iss. SI.

Meyer, J. S., Santore, R. C., Bobbitt, J. P., Debrey, L.D., Boese, C. J., Paquin, P. R., Allen, H. E., Bergman, H. L., and Ditoro, D. M., 1999, Binding of nickel and copper to fish bills predicts toxicity when water hardness varies, but free-ion activity does not: Environmental Science and Technology, v. 33, p. 913916.

Møller, C., and Plessett, M. S., 1934, Note on an approximation treatment for many-electron systems: Physical Review, v. 46 , p. 618

Morgan, D. D., Warshawsky, D., and Atkinson, T., 1977, The relationship between carcinogenic activities of polycyclic aromatic hydrocarbons and their singlet, triplet, and singlet-triplet splitting energies and phosphorescence lifetimes: Photochemistry and Photobiology, v. 24, p. 31-38.

Murphy, E. M, Zachara, J. M., and Smith, S. C., 1990. Influence of mineral-bound humic substances on the sorption of hydrophobic organic compounds: Environmental Science and Technology, v. 24, p. 15071516.

Murphy, E. M., Zachara, J. M., Smith, S. C., and Phillips, J. L., 1992, The sorption of humic acids to mineral surfaces and their role in contaminant binding: Science of the Total Environment, v. 117/118, p. 413-423.

Neal, A. L., Rosso, K. M., Geesey, G. G., Gorby, Y. A., and Little, B. J., 2003, Surface structure effects on direct reduction of iron oxides by Shewanella oneidensis: Geochimica et Cosmochimica Acta, v. 67, p. 4489 4503.

Palotas, A. B., Rainey, L. C., Feldermann, C. J., Sarofim, A. F., and VanderSande, J. B., 1996, Soot morphology: An application of image analysis in high-resolution transmission electron microscopy: Microscopic Research Techniques, v. 33, p. 266-278.

Parthasarathi, R., Padmanabhan, J., Subramanian, V., Maiti, B., and Chattaraj, P. K., 2003, Chemical reactivity profiles of two selected polychlorinated biphenyls: Journal Physical Chemistry A, v. 107, p. $10346-10352$.

Penning, T. M., 1993, Dihydrodiol dehydrogenase and its role in polycyclic aromatic hydrocarbon metabolism: Chemico-Biological Interactions, v. 89, p. 1-34.

Perlow, R. A., and Broyde, S., 2001, Evading the proofreading machinery of a replicative DNA polymerase: Induction of a mutation by an environmental carcinogen: Journal of Molecular Biology, v. 309, p. 519-536.

2002, Toward understanding the mutagenicity of an environmental carcinogen: Structural insights into nucleotide incorporation preferences: Journal of Molecular Biology, v. 322, p. 291-309.

_ 2003, Extending the understanding of mutagenicity: Structural insights into primer-extension past a benzo[a] pyrene diol epoxide-DNA adduct: Journal of Molecular Biology, v. 327, p. 797-818.

Perlow, R. A., Kolbanovskii, A., Hingerty, B. E., and others, 2002, DNA adducts from a tumorigenic metabolite of benzo[a]pyrene block human RNA polymerase II elongation in a sequence- and stereochemistry-dependent manner: Journal of Molecular Biology, v. 321, p. 29-47.

Perrin, J., Poirot, N., Liska, P., Hanras, C., Theinpoint, A., and Felix, G., 1993, Trace enrichment and HPLC analysis of PAHs in edible oils and fat products, using liquid chromatography on electron acceptor stationary phases in connection with reverse phase and fluorescence detection, in Garrigues, P., and Lamotte, M., editors, Proceedings $13^{\text {th }}$ International Symposium on Polynuclear Aromatic Hydrocarbons: Langhorne, Pennsvlvania, Gordon and Breach Science Publishers, p. 31-41.

Phillips, D. H., 1999, Polycyclic aromatic hydrocarbons in the diet: Mutation Research, v. 443, p. $139-147$.

Pignatello, J. J., 1986, Ethylene dibromide mineralization in soils under aerobic conditions: Applied and Environmental Microbiology, v. 1, p. 588-592.

Pisutpaisal, N., ms, 2003, Sorption and biodegradation of ionizable polycyclic aromatic hydrocarbons (IPAHs) in estuarine sediment: Ph.D. thesis, The Pennsylvania State University, University Park, Pennsylvania.

Reddy, C. M., Pearson, A., Xu, L., McNichol, A. P., Benner, B. A., Wise, S. A., Klouda, G. A., Currie, L. A., and Eglinton, T. I., 2002, Radiocarbon as a tool to apportion the sources of polycyclic aromatic hydrocarbons and black carbon in environmental samples: Environmental Science and Technology, v. 36 , p. 1774-1782.

Richnow, H. H., Seifert, R., Hefter, J., Kastner, M., Mahro, B., and Michaelis, W., 1993, Metabolites of xenobiotica and mineral oil constituents linked to macromolecular organic matter in polluted environments: Advances in Organic Geochemistry, v. 22, p. 671-681.

Schultz, T. W., Cronin, M. T. D., Walker, J. D., and Aptula, A. O., 2003, Quantitative structure-activity relationships (QSARs) in toxicology: a historical perspective: Journal Molecular Structure-Theochem, v. 622 , p. $1-22$.

Schwarzenbach, R. P., Gschwend, P. M., and Imboden, D. M., 1993, Environmental organic chemistry: New York, John Wiley and Sons, $681 \mathrm{p}$.

Schmidt, W., 1977, Photoelectron spectra of polynuclear aromatics. v. Correlations with ultraviolet absorption spectra in the cata-condensed series: Journal of Chemical Physics, v. 66, p. 828-845.

Semple, K. T., Morriss, A. W. J., and Paton, G. I., 2003, Bioavailability of hydrophobic organic contaminants in soils: fundamental concepts and techniques for analysis: European Journal of Soil Science, v. 54, p. $809-818$.

Shida, T., 1988, Electronic absorption spectra of radical ions: Amsterdam, Elsevier, Physical Science Data, v. 34 , p. xiv + p. 446 .

Shoemaker, J. R., Burggraf, L. W., and Gordon, M. S., 1999, SIMOMM: An integrated molecular orbital/ molecular mechanics optimization scheme for surfaces: Journal of Physical Chemistry A, v. 103, p. 3245-3251. 
Smith, D. M., and Chughtai, A. R., 1995, The surface structure and reactivity of black carbon, Colloids and Surfaces A: Physicochemical and Engineering Aspects, v. 105, p. 47-77.

Stewart, J. J. P., 1989, Optimization of parameters for semi-empirical methods. 1. Method: Journal of Computational Chemistry, v. 10, p. 209-220.

1990, Special Issue-MOPAC-A semiempirical molecular-orbital program: Journal of Computer Aided Molecular Design, v. 4, p. 1-45.

2004, Comparison of the accuracy of semiempirical and some DFT methods for predicting heats of formation: Journal of Molecular Modeling, v. 10, p. 6-12.

Stewart, M. A., Jardine, P. M., Brandt, C. C., Barnett, M. O., Fendorf, S. E., and McKay, L. D., Mehlhorn T. L., and Paul, K. 2003, Effects of contaminant concentration, aging, and soil properties on the bioaccessibility of $\mathrm{Cr}(\mathrm{III})$ and $\mathrm{Cr}(\mathrm{VI})$ in soil: Soil and Sediment Contamination, v. 12, p. 1-21.

Stratmann, R. E., Scuseria, G. E., and Frisch, M. J., 1998, An efficient implementation of time-dependent density-functional theory for the calculation of excitation energies of large molecules: Journal of Chemical Physics, v. 109, p. 8218-8224.

Sun, H., 1998, COMPASS: An ab initio force-field optimized for condensed-phase applications-Overview with details on alkane and benzene compounds: Journal of Physical Chemistry, v. 102, p. 7338-7364.

Sunda, W. G., and Huntsman, S. A., 1998, Processes regulating cellular metal accumulation and physiological effects: Phytoplankton as model systems: Science of the Total Environment, v. 9, p. 165-181.

Tancell, J. T., Rhead, M. M., Pemberton, R. D., and Braven, J., 1995, Survival of polycyclic aromatic hydrocarbons during diesel combustion: Environmental Science and Technology, v. 29, p. 2871-2876.

Trohalaki, S., and Pachter, R., 2003, Quantum descriptors for predictive toxicology of halogenated aliphatic hydrocarbons: SAR and QSAR in Environmental Research, v. 14, p. 131-143.

Urban, J. J., Cramer, C. J., and Famini, G. R., 1992, A computational study of solvent effects on the conformation of dopamine: Journal of the American Chemical Society, v. 114, p. 8226-8231.

USEPA, 2000, Technical basis for the derivation of equilibrium partitioning sediment guidelines (ESGs) for the protection of benthic organisms: Washington, D. C., USEPA.

Veith, G. D., Mekenyan, O. G., Ankley, G. T., and Call, D. J., 1995, A QSAR analysis of substituent effects on the photoinduced acute toxicity of PAHS: Chemosphere, v. 30, p. 2129-2142.

Wang, Y., and Perdew, J. P., 1991, Spin scaling of the electron-gas correlation-energy in the high-density limit: Physical Review B, v. 43, p. 8911-8916.

Wania, F., and McLachlan, M. S., 2001, Estimating the influence of forests on the overall fate of semivolatile organic compounds using a multimedia fate model: Environmental Science and Technology, v. 35, p. 582-590.

Wernersson, A. S., 2003, Predicting petroleum phototoxicity: Ecotoxicology and Environmental Safety, v. 54, p. 355-365.

Wilson, A. S., Davis, C. D., Williams, D. P., Buckpitt, A. R., Pirmohamed, M., and Park, B. K., 1996, Characterisation of the toxic metabolite(s) of naphthalene: Toxicology, v. 114, p. 233-242.

Wilson, M. S., and Madsen, E. L., 1996, Field extraction of a transient intermediary metabolite indicative of real time in situ naphthalene biodegradation: Environmental Science and Technology, v. 30, p. 20992103.

Zhang, Z., Fenter, P., Cheng, L., Sturchio, N. C., Bedzyk, M. J., Predota, M., Bandura, A., Kubicki, J. D., Lvov, S. N., Cummings, P. T., Chialvo, A. A., Ridley, M. K., Bénézeth, P., Anovitz, L., Palmer, D. A., Machesky, M. L., and Wesolowski, D. J., 2004, Ion adsorption at the rutile-water interface: Linking molecular and macroscopic properties: Langmuir, v. 20, p. 4954-4969. 